\title{
DEVELOPMENT OF A CELL DEPOSITING SYSTEM USING INKJET TECHNOLOGY
}

\author{
A Thesis \\ Presented to \\ the Faculty of California Polytechnic State University \\ San Luis Obispo, California
}

In partial fulfillment

of the Requirements for the Degree

Master of Science in Engineering with a Specialization in Biomedical Engineering

by

Jason Robert Ozaeta

June 2008 
(C) 2008

Jason Robert Ozaeta

ALL RIGHTS RESERVED

ii 


\section{COMMITTEE MEMBERSHIP}

TITLE:

Development of a Cell-Depositing System Using Inkjet Technology

AUTHOR:

Jason Robert Ozaeta

DATE SUBMITTED:

June 2008

COMMITTEE CHAIR: $\quad$ Robert Crockett, Director of Biomedical/General Engineering Program

COMMITTEE MEMBER: $\quad$ Kristen O’Halloran Cardinal, Assistant Professor, Biomedical/General Engineering

COMMITEE MEMBER: $\quad$ Daniel Peterson, Assistant Professor, Animal Sciences 


\section{ABSTRACT \\ Development of a Cell-Depositing System Using Inkjet Technology Jason Robert Ozaeta}

In the past decade, advances in tissue engineering have allowed researchers to fabricate simple tissues. However, the process of creating these native tissues is a time consuming and inefficient process. A scaffold must first be fabricated then exposed to a sea of cells in the hopes of seeding. Furthermore, even though cells may have attached, more time must be spent in order to allow the cells to migrate to their ideal locations. To deal with this problem, researchers have investigated whether rapid prototyping principals could be adapted to facilitate the cell seeding process by placing cells in their respective locations during scaffold fabrication. The goal for this thesis was to establish the foundation for a cell-compatible printer that, in the future, could fabricate pre-seeded scaffolds. This task included implementing changes to a commercial solenoid-based inkjet system that would allow cells to be loaded into the printer in a sterile fashion. In addition, protocols had to be designed with system limitations in mind. An initial test with the designed system showed a majority of cell viability percentages above $90 \%$. If additional tests confirm this possibility, the system should be further modified to provide cells with a proper culturing environment. Furthermore, additional research would need to be performed in order to determine whether scaffolding materials can be dispensed through the system to fabricate scaffolds. 


\section{TABLE OF CONTENTS}

List of Figures .................................................................................................... vii

1.0: INTRODUCTION ........................................................................................................ 1

2.0: TISSUE ENGINEERING FUNDAMENTALS ................................................... 4

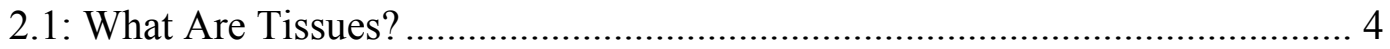

2.2: The Extracellular Matrix......................................................................... 5

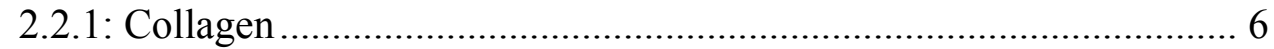

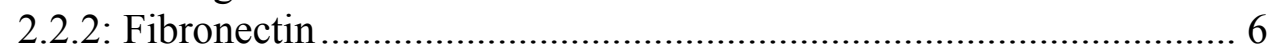

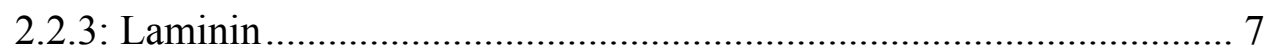

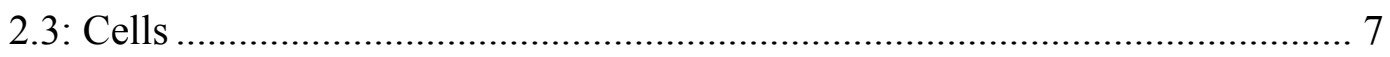

2.3.1: Autologous Cells .......................................................................... 8

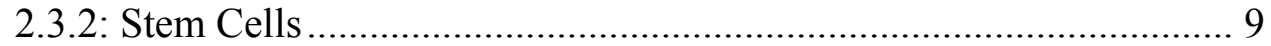

2.3.3: Progenitor Cells ……………………………………………..... 10

2.4: Natural Scaffold Materials ........................................................................ 11

2.4.1: ECM-based Polymer Scaffolds..................................................... 12

2.4.2: Other Natural Polymer Scaffolds.................................................. 13

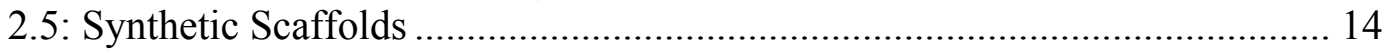

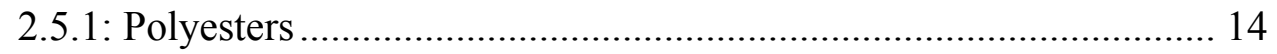

2.5.2: Poly(ethylene glycol) …………………………….................... 15

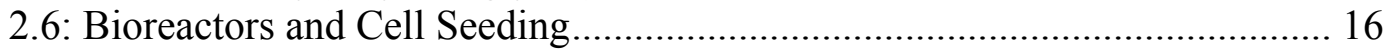

2.6.1: Static Culture ………………………………………………....16

2.6.2: Spinner Flask Bioreactor .............................................................17

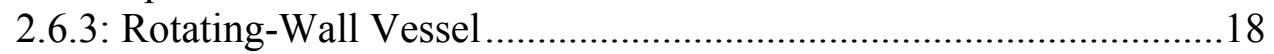

2.6.4: Perfusion Bioreactors....................................................................... 18

2.6.5: Bioreactor Design Considerations ..................................................19

2.7: Dealing With Limitations of Current TE Techniques ....................................20

3.0: RAPID PROTOTYPING IN TISSUE ENGINEERING .......................................22

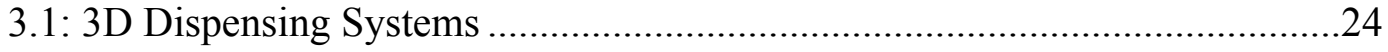

3.1.1: Direct Inkjet Printing ....................................................................24

3.1.2: Fused Deposition Modeling.............................................................25

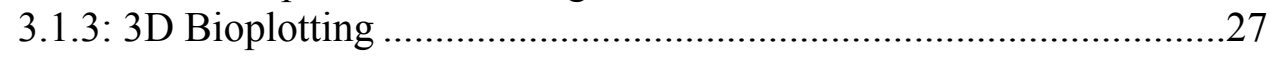

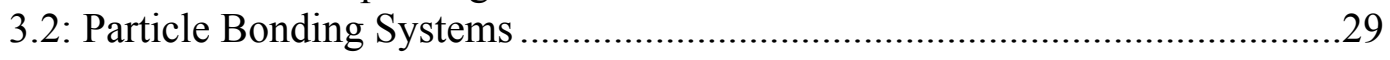

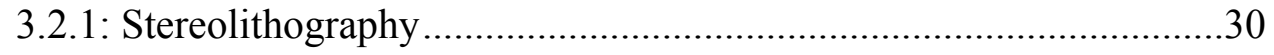

3.2.2: Selective Laser Sintering ................................................................. 31

3.2.3: 3D Printing .....................................................................................33

3.3: Choosing the Most Appropriate RP System ..................................................36

4.0: INKJET TECHNOLOGY AND ITS ROLE IN CELL PATTERNING...............38

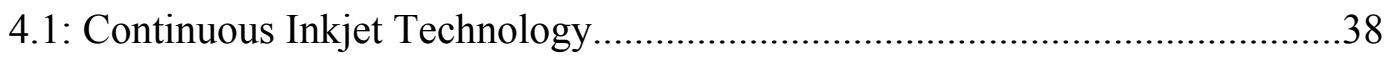

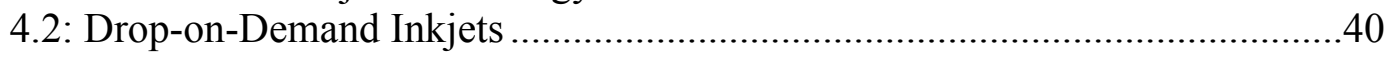

4.2.1: Thermal Inkjets ............................................................................ 41 
4.2.2: Piezoelectric Inkjets ......................................................................42

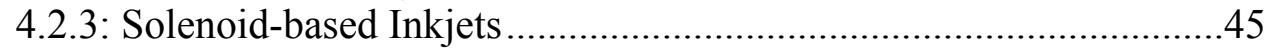

4.3: Is a Smaller Droplet Better?...................................................................... 47

5.0: DEVELOPING THE CELLULAR INKJET SYSTEM ......................................50

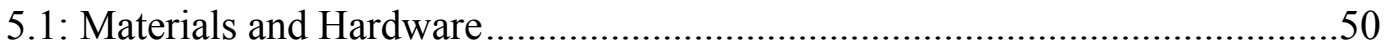

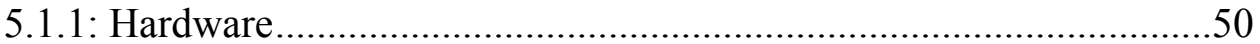

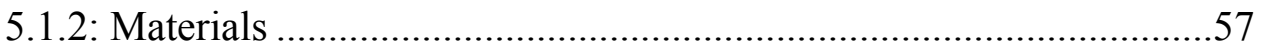

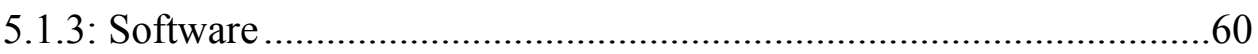

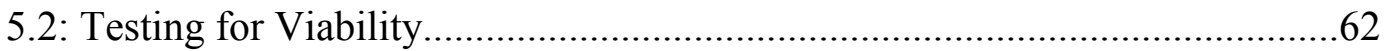

5.2.1: Cell-specific Resources and Caveats ...............................................63

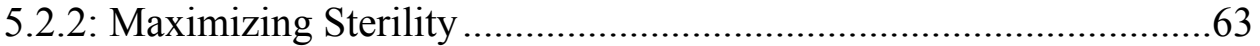

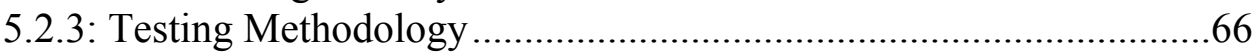

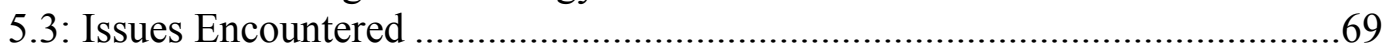

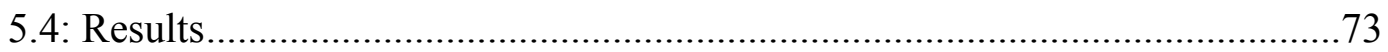

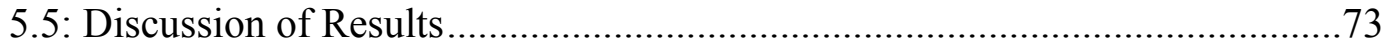

6.0: FUTURE WORK AND CONCLUSION ...................................................................74

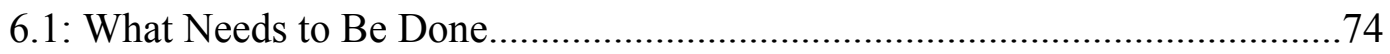

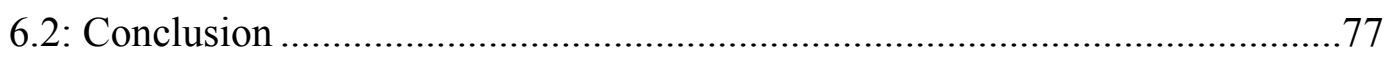

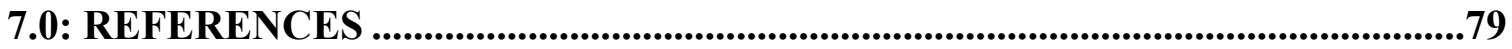

APPENDIX A: GLUTARALDEHYDE PREPARATION PROTOCOL.....................86

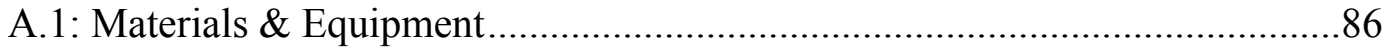

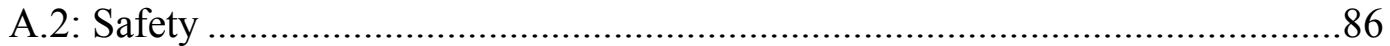

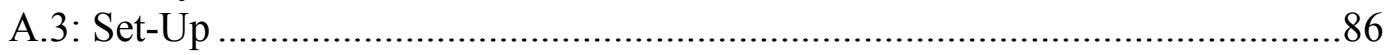

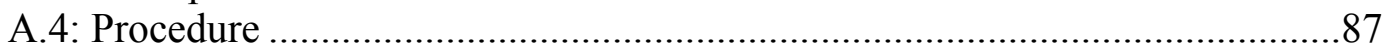

APPENDIX B: INKJET RESERVOIR ASSEMBLY PROTOCOL .............................88

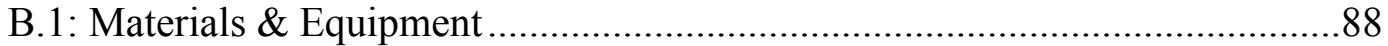

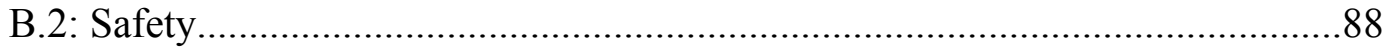

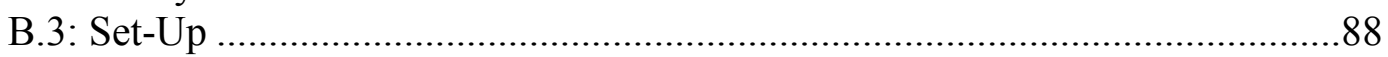

B.4: Procedure

APPENDIX C: INKJET LOADING PROTOCOL ................................................90

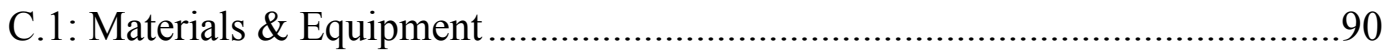

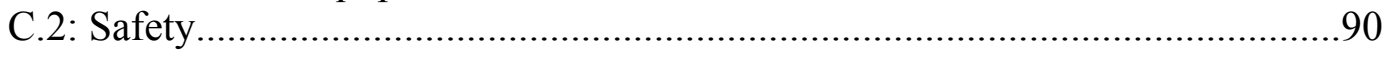

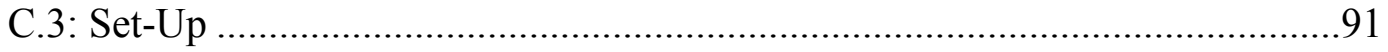

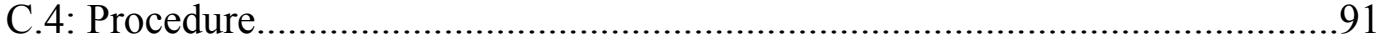

APPENDIX D: INKJET UNLOADING PROTOCOL ...................................................92

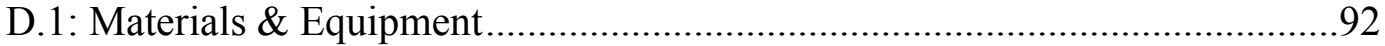

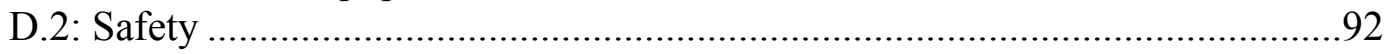




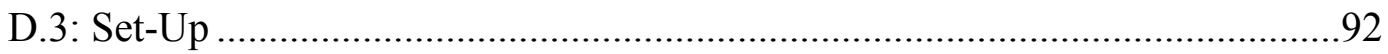

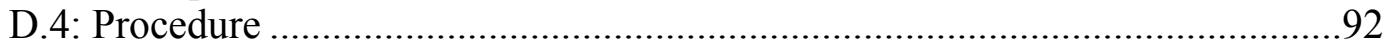

APPENDIX E: TRYPAN BLUE ASSAY PROTOCOL ..............................................94

E.1: Materials \& Equipment ...........................................................................99

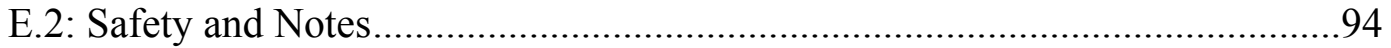

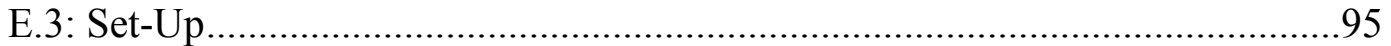

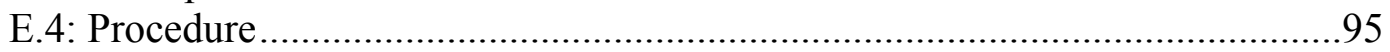

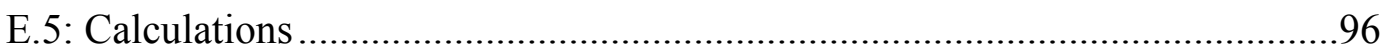

APPENDIX F: CELL PRINTER TEST PROTOCOL ...........................................97

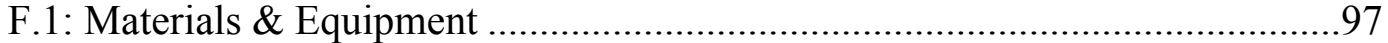

F.2: Safety and Notes ............................................................................ 97

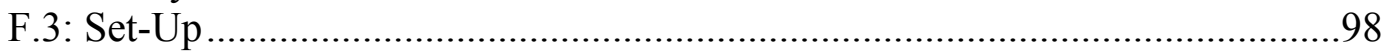

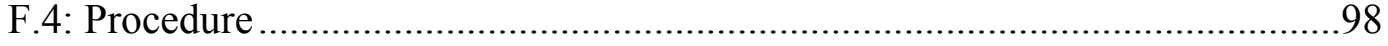

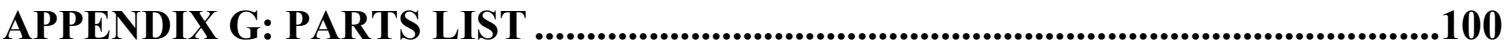




\section{LIST OF FIGURES}

Figure 2.1: Schematic drawing of a spinner flask bioreactor ...................................... 17

Figure 2.2: Example of a NASA-designed rotating-wall vessel ................................. 18

Figure 3.1: Schematic diagram of a typical FDM system ........................................... 26

Figure 3.2: Schematic drawing of a typical 3D bioplotter ....................................... 28

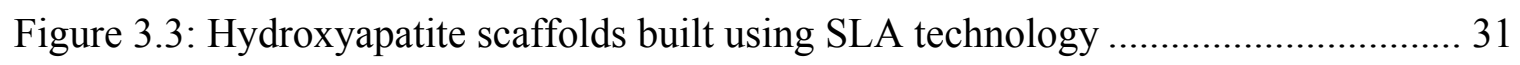

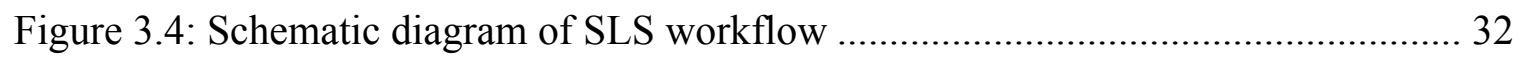

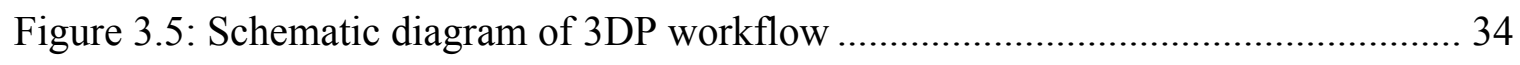

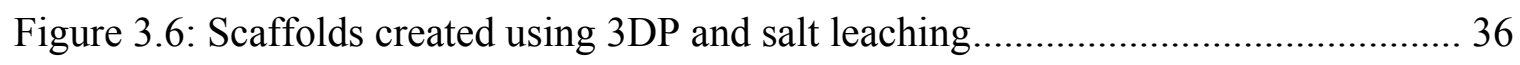

Figure 4.1: Schematic illustration of binary-deflection continuous ink jet .................... 41

Figure 4.2: Schematic illustrations of different piezo inkjet modes ............................. 43

Figure 4.3: Poisson distributions of various cell per drop averages ............................ 48

Figure 5.1: Inside the printer, showing the nozzle array and print heads ...................... 51

Figure 5.2: A sample vent filter is attached to top of syringe screw-cap........................ 54

Figure 5.3: Spike and hold circuit with power and inkjet wires connected .................... 56

Figure 5.4: Chart plotting detected solenoid temperatures during repetitive dispensing . 56

Figure 5.5: Nalgene tubing with pinch clamp and luer-locks on syringe tip .................. 58

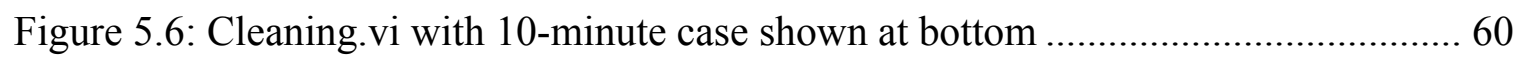

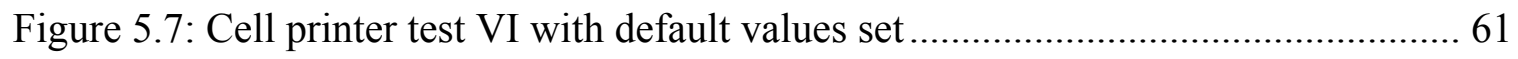

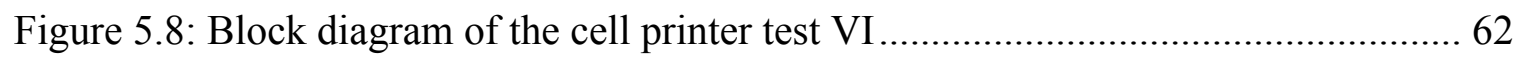

Figure 5.9: Assembled reservoir in laminar flow hood, filled with glutaraldehyde ......... 65

Figure 5.10: Inkjet system during purging with $2.5 \%$ glutaraldehyde ......................... 68

Figure 5.11: Light microscope showing viable cells in a printed solution ...................... 71 
Figure 5.12: Calculated data from print vs. control group... 


\subsection{INTRODUCTION}

There is a growing concern in the medical field regarding tissue damage treatments, where a declining trend can be seen in tissue availability. For example, the number of U.S. patients on the kidney transplant active waiting list is increasing. In 1996, the waiting list had about 29,000 patients; in 2006, there were over 45,000. In contrast, the number of patients that actually received a transplant increased from about 10,000 to only about 16,000 patients [61]. This widening gap in transplant supply-anddemand demonstrates that organ transplant surgery is unable to meet the growing demand for tissue. Furthermore, the few patients that are able to receive the vital organ transplant will most likely require immunosuppressant therapy for the rest of their lives to prevent tissue rejection. Other options for tissue-replacement patients do not offer much potential, either. Surgical reconstruction, for example, is affected by similar donor shortage problems, as well as the risk of donor site morbidity. The third option, artificial organs and/or mechanical intervention, puts patients at risk for thrombosis and infection. Furthermore, mechanical devices currently have a limited lifespan [16]. With these limitations in mind, researchers looked for a new way to tackle the rising tissue shortage. In 1987, researchers established a new field of study to specifically tackle this tissue shortage. Tissue engineering is defined as an interdisciplinary field that applies the principles of engineering and life sciences towards the development of biological substitutes that restore, maintain, or improve tissue function [69]. This field combines the efforts of cell biologists, engineers, material scientists, mathematicians, geneticists, and clinicians to fabricate new tissue that can mimic native tissue function [16]. Furthermore, to serve as a better alternative than the previously mentioned clinical 
treatments, these engineered tissues also need to elicit no major immunogenic responses. Tissue engineering potentially can offer doctors the ability to repair damaged tissue much more effectively than current clinical methods.

The current technique for engineering tissue, described in greater detail later in this paper, involves the use of pre-made scaffolds, which are 2D or 3D structures onto which cells can adhere to and develop on. These scaffolds, which also facilitate nutrient transport and provide mechanical support for the cells, require a complex network of interconnecting pores for adequate nutrient diffusion throughout the structure [31]. This complex pore network, however, cannot easily be fabricated using traditional manufacturing techniques. Furthermore, depending on the size of the scaffold, the cells cannot always diffuse through the entire scaffold to fully seed the construct. These issues stress a need for a better method of tissue fabrication.

Researchers began to investigate another recently developed technology to possibly resolve these issues. Rapid prototyping (RP) evolved out of a need to visualize and test a product without sacrificing time. The key to rapid prototyping is cheap, easily fused/bound material(s) and a layer-based assembly method. For tissue engineers, however, the ability to build complex shapes layer-by-layer could allow for the creation of better scaffolds. By creating an interconnected porous substructure, researchers believe that these scaffolds will allow for better tissue properties.

However, while RP systems have been increasingly used for scaffold research, relatively few studies have been examined the possibility of RP-based cell seeding. Although RP devices can build a scaffold on-demand, most researchers still seed cells the "classical" way, following scaffold production. If a scaffold can be built layer-by-layer 
to generate complex patterns, why can't the same system also strategically place cells for better migration and tissue function? Since tissues rely on groups of cells that are not randomly distributed within its matrix, tissue-engineering techniques should be designed to best place the cells without relying too heavily on uniform cell distribution to achieve this goal.

This thesis project was intended to create a proof-of-concept for a potential RP system that is capable of seeding cells onto specific locations. An existing commercial ink-jet system was modified to accept a variety of fluids. A closed-system fluid reservoir was developed to maximize sterility at the inlet, and a protocol was developed to maximize the system's sterility prior to depositing cells. If everything works as planned, this system should be able to dispense viable cells. The long-term goal for this project is to develop a novel, low-cost RP system capable of constructing a 3D bioactive scaffold autonomously. The multiple ink-jet heads should make it possible to dispense different materials simultaneously. As a result, it should be possible, in the future, to integrate cells into a scaffold as the construct is being built. While far from complete realization, achieving such a goal could lead to the solution for our growing tissue shortage. 


\section{$\underline{2.0}$ TISSUE ENGINEERING FUNDAMENTALS}

The field of tissue engineering requires a vast body of information. This large knowledge base comes from the wide variety of disciplines involved in this research field. Therefore, to understand this interdisciplinary field, one needs to understand the basics of some of these disciplines. On the biological side, one should be familiar with the individual components in the body that allow for tissue formation: the extracellular matrix, cells, and other stimuli. Because this field is still relatively young, new and different techniques are always being developed, and sometimes can be hard to follow. Therefore, one should also understand the basic fundamentals of the classical tissue engineering approach in order to understand the need for researching new techniques.

\subsection{What Are Tissues?}

Tissues can be defined as a collection of similar cells that perform a common function. In order to understand this definition, one should consider differences between unicellular and multi-cellular organisms. A unicellular organism is the most basic of organisms, dedicated to performing a single function. Multi-cellular organisms, as implied by its name, contain many cells. If one assumes that different cells perform different functions, then a multi-cellular organism could potentially perform more complex functions. In a competitive environment, these organisms need to maximize its survivability. As a result, organization of the cells is required, as grouping similar cells or cells that work best together can optimize throughput. These groupings ultimately lead to a separation of specialized cells, better known as a tissue. 
Tissues can be classified into four major categories: muscle, connective, nervous, and epithelial. The primary function of all muscle tissue is to provide contractile force. In comparison to muscles, connective tissue provides little or no contractile force. As its name implies, this form of tissue connects and provides support to various parts of the body. Nervous tissue provides the body with a quick communication system. This tissue is comprised of many neurons that synapse together to form a communication pathway. Epithelial tissue allows the body to maintain homeostasis, mainly by providing protective barriers and facilitating with water retention.

\subsection{The Extracellular Matrix}

In tissue engineering, researchers must be able to recreate an environment ideal for supporting tissue growth. Part of this ability involves replicating or simulating parts of tissues needed for cell attachment and other sustaining functions. Looking at one of the individual tissue components, the extracellular matrix (ECM) is a three-dimensional network of macromolecules in which smaller molecules, such as proteins, ions, and water, are bound to [15]. This matrix provides both structure and support for the smaller molecules. The ECM also provides a number of other functions, such as ion balance, intercellular communication, and cell migration/adhesion. These various functions allow for the growth of cells into tissue. This section will provide a brief describe several ECM components that have been utilized by other researchers for cell patterning. 


\subsubsection{Collagen}

Collagen, which is the most abundant protein in the body, serves as an aggregate to form various macrostructures, such as fibrils, basement membranes, filaments, canals and sheets. Currently, there are 27 known types of collagen and proteins with collagenlike domains [15]. Of these 27 types, types I, II, and III are the most abundant forms of collagen found in the body. Type I collagen is found mostly in connective tissue, such as the skin, tendons, and bone; type III collagen is usually found with type I collagen. Type II collagen can be found in cartilage [26]. These types of collagen are usually synthesized by fibroblasts in precursor form, and then are processed once secreted into the ECM [23]. Because of its affinity for cell attachment, tissue engineers have used this component to provide specific attachment sites for cells used in their research. Roth et al., for example, used collagen in a commercial printer and patterned collagen onto a glass coverslip [47]. This technique created a pattern of cell attachment sites surrounded by cell-repellant material, which would dictate where cells would attach.

\subsubsection{Fibronectin}

Fibronectin, one of the first ECM proteins to be characterized, is important in attaching cells to the ECM. This molecule is rod-like in structure and is comprised of three domain types that serially repeat [1]. Of the three repeatable domains, type III fibronectin repeat is the most common domain. This domain contains a pep-tide sequence arginine-glycine-aspartic acid, also known as RGD, which has been shown to be an important feature of the domain's binding site [1]. Utilizing this characteristic, Klebe et al. have investigated the possibility of printing fibronectin onto substrates for 
patterned cell attachment [27]. Like research by Roth et al., Klebe et al's research did not include printing cells directly, but rather demonstrated that printers could be used to influence and direct cell attachment by controlling where the cell attachment sites are.

\subsubsection{Laminin}

As its name might imply, laminin is found in basal laminae, which are thin "mats" of ECM that underlie epithelial vessels and surround muscle and adipose tissue [1]. The basal laminae serve as a separation layer between the previously mentioned tissues and surrounding connective tissue. Many cells use the laminin as a sub-stratum for cell migration [15]. Furthermore, laminin also is believed to promote neuronal growth. Because of these features, researchers, like Turcu et al., have used laminin to serve as cell adhesion sites, similar to research using collagen and fibronectin [57]. In their research, a custom dispensing system was created that allowed the researchers to create patterns of a laminin mixture on various substrates. As expected, neuronal cells adhered mainly along the printed laminin pattern. Their results, along with Klebe and Roth, show that printers have potential application for cell patterning.

\subsection{Cells}

The other vital components for engineering a tissue are cells. Living cells need to be obtained in order to proliferate and differentiate into the desired cells. Once obtained, these cells are cultured repeatedly to increase its population to a useable size. Because the cells are alive, a proper environment must be maintained to maximize their longevity. 
Also, the cultured cells need to be occasionally assessed to ensure they are still usable.

This section will briefly review various types of cells currently in use by tissue engineers.

\subsubsection{Autologous Cells}

A number of cell types, categorized by their source, are used in tissue engineering applications. Autologous cells are the most ideal cells to use for a few reasons. These cells are obtained from the patient, usually through a biopsy. As a result, autologous cells have the main advantage in eliminating any chance of an immunogenic reaction, since the cells would express the patient's own native surface markers. If the target tissue is present and healthy, the patients own cells would be especially advantageous during culturing. Cells from target tissues often are already differentiated, so chemical stimulation with growth factors is not needed as much to induce desired tissue function. This cell type has been successfully applied in tissue reconstruction. In research by Atala et al., cells were obtained via biopsy samples from the bladders of several patients with myelomeningocele [3]. Each individual's cells were cultured, seeded onto a synthetic bladder scaffold (which will be discussed in the next section), and cultured. The resulting constructs were then implanted in their respective patient. Following surgery, most of the patients saw improved bladder and bowel functionality. Furthermore, no significant immunogenic reactions or rejection took place. Atala's results demonstrated that autologous cells can produce tissue with proper physiologic function and little rejection or reaction.

While obtaining cells from the patient's own target tissue would be an ideal condition for culturing the same tissue, this method has some disadvantages as well. 
First, few cells are easily accessible for harvesting. Elderly patients or patients with diseased tissue, for example, will most likely yield few, if any, healthy cells [21]. Furthermore, the cells may not be available at all if the target tissue was removed prior to its need. Because these cells are obtained from target tissue, they are severely limited in the types of tissue it can differentiate into. Due to these restrictions, other sources of autologous cells have been researched for tissue engineering.

\subsubsection{Stem Cells}

Recently, stem cells have been used to generate larger quantities of tissue. Two types of stem cells are currently used in research. Embryonic stem cells are, as its name implies, obtained from embryos. Adult stem cells, on the other hand, are obtained from various locations on an adult's body. Unlike differentiated cells, stem cells are able to differentiate into a number of cells. However, the difficulty in achieving this variation depends on the type of stem cell.

Recently, five cell lines, derived from blastocytes in human embryos, were shown to be pluripotent; in other words, they were shown to be able to differentiate into virtually any cell type [21]. These embryonic stem cells (ESCs) were believed to exhibit unlimited self-renewal. As a result, it could have been possible to culture almost any tissue with this single cell line. However, the controversial use of this cell type made it difficult to acquire funding; human embryonic stem cell research could not qualify for National Institute of Health funding unless cells were obtained from embryos before August 9, 2001 [62]. So while this cell type offered significant advantages, ethical issues limited its use in research. 
As an alternative to ESCs, adult stem cells (ASCs) offer similar advantages but without the controversy. Unlike ESCs, adult stem cells are not obtained from embryos, but rather in tissues of living animals. For example, the most "common" adult stem cell, mesenchymal stem cells (MSCs), could be obtained in multiple tissues, such as muscle, cartilage, bone marrow, liver, and pancreas [21]. Despite the many locations, these cells are incredibly rare within the body. Often, researchers are unable to obtain sufficient numbers of ASCs needed for transplantation and cultivation. However, these rare cells offer great potential. These cells are believed to exist in tissues in order to maintain homeostasis. The cells become activated when tissue damage occurs. Like ESCs, ASCs are also capable of self-renewal for the lifetime of the organism. More importantly, ASCs are undifferentiated. Because of this trait, ASCs could be induced to differentiate into a wide variety of cells. While was is difficult to prove that these cells were pluripotent, many studies did support the belief that ASCs were at least multipotent. In one study, for example, hematopoietic stem cells from one mouse were shown to completely regenerate lethally irradiated hematopoietic systems of other mice [62]. This amazing feat demonstrated the enormous potential that ASCs had for tissue engineers.

\subsubsection{Progenitor Cells}

Progenitor cells are technically intermediates of the stem cell, but have significantly different characteristics. While stem cells are undifferentiated, progenitor cells are "committed" towards differentiating along a certain pathway; in other words, these cells are partially differentiated. When stem cells divide, at least one identical cell is created, hence the self-renewing characteristic. On the other hand, when progenitor 
cells divide, both resulting cells are further differentiated. As a result, these cells eventually result in a fully differentiated cell. However, since these cells initially have different development pathways, progenitor cells are considered multipotent. For example, researchers have used mesenchymal progenitor cells to grow muscle, bone [69, 37], cartilage [66], tendon [28], and vascular tissue. While these cells have the ability to differentiate into many cell types, a lot of work involving biological, physical, and chemical stimuli is required. Furthermore, like adult stem cells, progenitor cells are fairly rare in the body. It is also difficult to distinguish between ASCs and progenitor cells, though progenitor cells could be isolated using markers specific to certain cell phenotypes.

\subsection{Natural Scaffold Materials}

Researchers are using the knowledge gained about the ECM to develop techniques for synthetically engineering tissue. Currently, tissue engineers utilize a prebuilt, engineered scaffold, which is a three-dimensional structure that serves as a support matrix for cells to restore, maintain, or improve tissue [70]. Both natural, ECM-based and synthetic, polymeric materials are used to create these structures. One of the ways the scaffold supports the cells is by providing an adherent surface for the cells to proliferate and differentiate. In addition to an adherent surface, scaffolds may also provide mechanical support to the cells. Furthermore, scaffolds must also allow for nutrient and waste transport to sustain cells that migrate. Because these constructs are eventually going to be implanted, researchers have to account for any immunogenic reactions that a foreign material could induce. Although this project is dedicated to cell 
deposition, scaffolds will still be used by this system. Researchers are also investigating the possibility of fabricating complex scaffolds using rapid prototyping techniques, which will be explained in a later chapter. Because a future goal for this system will be the ability to fabricate a scaffold and simultaneously seed cells during fabrication, the following two sections will briefly discuss scaffold materials that could be used in such a system.

\subsubsection{ECM-based Polymer Scaffolds}

Since the goal of the scaffold is to emulate parts of the ECM, natural ECM components could be used as scaffold materials. For example, scaffolds have been coated with hyaluronic acid to improve the scaffold's cell-adhesion [30]. Although the primary structure of this scaffold was fabricated using a synthetic polymer, the use of this ECM component demonstrated that such a material could be integrated to add specific characteristics. ECM components do not have to be relegated to just secondary scaffold functions, however. For example, derivatives of hyaluronic acid have even been successfully used as the primary scaffolding material for adipose precursor cells [20].

Collagen is another ECM component that has been used for creating scaffolds. Collagen has a number of adhesion domains that provide a surface for cell attachment. Because collagen promotes blood coagulation, it has been used as a scaffold for epithelial cells, such as fibroblasts and keratinocytes [70]. Furthermore, this scaffold material has been shown to allow rat hepatocytes to function. While a bioactive and biocompatible material, collagen has numerous forms that lead to high variability. Also, a natural component, it has a high degradation rate. 


\subsubsection{Other Natural Polymer Scaffolds}

Other natural materials have been used to create scaffolding for cells, each with its own set of advantages and problems. Gelatin, which is derived from collagen, has served as a natural scaffold material. To form gelatin, collagen is denatured into single polypeptide chains. This material is water-soluble, and forms into a hydrogel through temperature changes, which can then be stabilized for use as a scaffold through glutaraldehyde cross-linking. As a hydrogel, gelatin has supported cells in orthopaedic applications, such as differentiating adipose-derived stem cells into chondrogenicexpressing cells [70].

Alginic acid, also known as alginate, is a viscous, hydrophilic polysaccharide that is found in the cell walls of brown algae. Alginate forms into a hydrogel when exposed to divalent ions, such as calcium, allowing it to be used as a scaffold. While not a native molecule in mammals, alginate has been shown to be biocompatible, as it does not contain any RGD attachment sites needed for cell adhesion. Furthermore, the presence of hydroxyl groups makes this molecule water-soluble. Despite the reduced likelihood for adhesion, various cells have been shown to successfully bind to and function on alginate scaffolds. For example, endothelial cells have successfully attached to custom alginate scaffolds without the need for any additional chemical or surface modifications [7]. In another study, rat hepatocytes seeded onto alginate sponges were able to secrete albumin, which demonstrates the seeded cells were functioning in the in-vitro scaffold [18]. More relevant to the scope of this project, alginate was used with a printer to rapid prototype a scaffold [7]. Rather than dispense the alginate, however, Boland et al. dispensed the 
cross-linker onto a pool of alginate. This experiment suggests that in addition to seeding cells, printers could also be used to build scaffolds.

\subsection{Synthetic Scaffolds}

Synthetic polymers offer a number of advantages over natural scaffolds. For example, most natural polymers offer some functionality desired for the scaffold, but can lack other vital characteristics. Synthetic polymers, on the other hand, can be engineered to meet specific mechanical or chemical requirements for the scaffold. Furthermore, most synthetic polymers undergo hydrolytic degradation, resulting in a more predictable degradation rate [70]. However, issues with biocompatibility could arise because the materials or its degradation products are usually not natural. Currently, over eleven synthetic polymers have been researched for use as scaffolds. Only the more commonly used polymers will be discussed below.

\subsubsection{Polyesters}

Polyesters make up the majority of synthetic polymers used in scaffolds. Poly(Llactic) acid (PLLA), is an example of a polyester. PLLA is a hydrophilic, crystalline polyester that exhibits a high melting point and degradation rate, as well as resistance to organic solvents. Furthermore, PLLA is also hydrophobic, making it appropriate for cell adhesion. To control the degradation rate and mechanical strength, PLLA can be copolymerized with poly(glycolic acid). This copolymer is amorphous, resulting in a lower degradation rate and mechanical strength when compared to PLLA [70]; degradation can last anywhere from a few weeks to a few years by varying the ratio of PGA and PLLA 
[52]. Lactic acid, the byproduct of PLLA degradation, is biocompatible, as mammals naturally break down this molecule during Kreb's cycle.

This degradable polyester has been extensively used in tissue engineering research. One study found that PLLA was able to support chondrocytes [70]. Another study found that a PLGA scaffold had a lower inflammatory response than a collagenbased hydrogel, while also showing higher integration with the host body [48]. PLLA has also been successfully engineered into an artificial anterior cruciate ligament [12]. Upon implantation, this artificial ligament induced relatively little immune reaction, while showing signs of vascularization. Finally, more relevant to this project, a study by Giordano et al. demonstrated how a printer could fabricate a PLLA structure [17]. These research projects show that PLLA has great potential for future tissue engineering applications.

\subsubsection{Poly(ethylene glycol)}

Poly(ethylene glycol) (PEG) is a linear polymer consisting of an ethylene oxiderepeating unit. As a hydrophilic molecule, this polymer can swell in aqueous solutions. On the other hand, its linear structure results in low mechanical stability [70]. Furthermore, by itself, PEG is non-degradable. However, the polymer can easily be cross-linked with other, degradable polymers to gain this ideal property. Another property of the polymer is its resistance to protein adsorption [13]. While this property may, at first, seem to be a disadvantage, researchers have used PEG to exploit this specific feature. In a study by Sanjana et al., for example, PEG was coated onto a glass coverslip to serve as a repulsive background [49]. A collagen-based mixture was then 
patterned, using an inkjet printer, over the PEG-coated coverslip to serve as an adhesive for the cells. Neuronal cells were then plated onto the entire coverslip. Because of the adhesive/repulsive substrates, the neuronal cells could only attach and migrate according to the patterned adhesive substrate.

\subsection{Bioreactors and Cell Seeding}

In a traditional tissue engineering process, once a scaffold is fabricated and the cells are ready, the cells need to be seeded onto the scaffold. This seeding occurs within a device called a bioreactor, which maintains an environment ideal for cell proliferation. The bioreactor achieves this environment in various ways. First, the scaffold is first exposed to the cells to allow for adhesion. During this process, bioreactors control temperature, gradients, and the size and shape of the scaffold. Furthermore, these devices also allow for the transport of nutrients and waste. Depending on the type of bioreactor used, additional forces could be added to stimulate certain characteristics while the cells proliferate. This stimulation factors heavily into how the cells proliferate, migrate, and differentiate. Therefore, for a traditional tissue engineering workflow, the bioreactor must be carefully chosen for the desired tissue characteristics.

\subsubsection{Static Culture}

The simplest type of seeding technique is a static culture. While this technique is not considered a bioreactor, it is worth mentioning for comparison. This seeding technique has been widely used for tissues that require a fibrous or porous material [2]. In this basic seeding technique, the scaffold is placed in a culture plate and submerged 
with a cell medium suspension and placed in an incubator. Depending on the cell type being used, this process could take from 24-48 hours to adequately seed cells. However, while this technique is the simplest to implement, it also yields the poorest results. A study comparing three seeding techniques found that static cultures had the worst surface and matrix distribution / attachment, and poor metabolic activity. Furthermore, this technique also gave the worst yield [8]. As a result of this low yield, more cells must be used to seed an adequate amount of cells.

\subsubsection{Spinner Flask Bioreactor}

The spinner flask is the simplest form of bioreactors. This type of bioreactor utilizes convection to seed and stimulate cells. To seed cells with this technique, the scaffolds are threaded onto rods attached to the flask's cover. The flasks are filled with the cell suspension, which infiltrates the scaffold once the cover is attached. A magnetic stir bar generates convection in the solution. This convection results in a turbulent eddies around the construct, which is believed to improve nutrient transport and expose surfaceattached cells to shear forces [2]. While intended to generate a homogenous cell distribution, the shear stresses are varied, resulting in a non-homogenous distribution. Ironically, while intended to maintain a well-mixed system, this dynamic seeding type actually performs worse than a static culture [8].

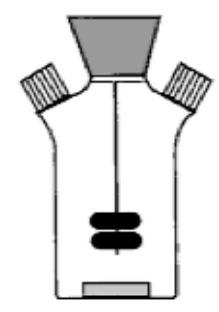

Figure 2.1 Schematic drawing of a spinner flask bioreactor [8] 


\subsubsection{Rotating-Wall Vessel}

The rotating-wall vessel has become the most widely used bioreactor design for bone, cartilage, and other tissues. This vessel, originally designed by NASA, is comprised of two concentric cylinders. The outer cylinder, which is linked to a rotor, houses the scaffold and cell/medium mixture. This outer cylinder rotates until the centrifugal forces negate gravitational forces. The inner cylinder, which does not rotate, is permeable for gas exchange. A huge advantage of the rotating-wall vessel is uniform tissue growth with no specific orientation; this characteristic is a result of the microgravity environment generated by the centrifugal forces. Furthermore, a rotatingwall vessel can create an almost uniform laminar flow with a consistent shear. These fluid flow characteristics can facilitate with establishing a homogenous cell distribution within the scaffold [2].

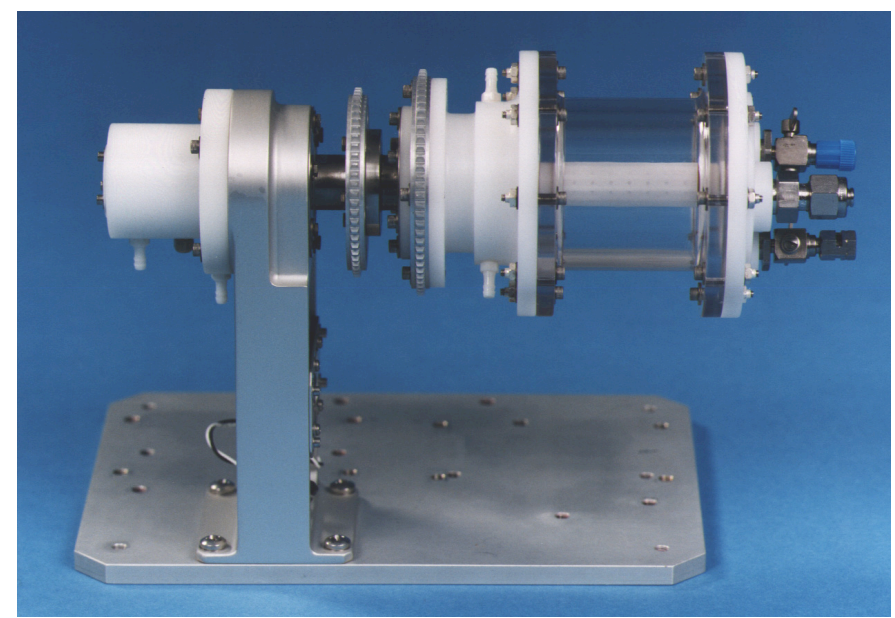

Figure 2.2 Example of a NASA-designed rotating-wall vessel [14]

\subsubsection{Perfusion Bioreactors}

Unlike spinner flasks and rotating wall vessels, flow perfusion bioreactors utilize no moving parts in the bioreactor chamber. In a perfusion bioreactor, the enclosed 
scaffold is exposed to a continuous fluid flow. Unlike the other bioreactor systems, this flow can be distributed between the scaffold, the surrounding environment, or both. These characteristics can allow for a controllable flow, which can improve nutrient transport. Furthermore, internal flow can expose the luminal surface to shear forces, which can facilitate the migration and differentiation of endothelial cells [2].

\subsubsection{Bioreactor Design Considerations}

While the three bioreactors mentioned above have been used to culture scaffolds, different cell types require different environments. As a result of this necessity, custom bioreactors are often developed to best mimic the native physiological environment. At a minimum, the bioreactor must maintain a temperature of $37^{\circ} \mathrm{C}$, humid atmosphere with a $5 \% \mathrm{CO}_{2}$ composition [2]. During the entire operation, the bioreactor must remain sterile. This requires a way to change culture aseptically and easily assemble the system. In order to induce the desired cell differentiation, the bioreactor needs to supply similar physiological stimuli to the scaffold. These stimuli could include any of the following: growth factors, pulsatile flow, compressive/tensile/ forces, and torsion [2].

When scaling up a bioreactor, cell distribution becomes a major concern. The bioreactor comparison study demonstrated that a bioreactor's effectiveness at establishing a homogenous cell distribution directly affects how well the cells attach and perform [8]. As the scaffold size increases, care will need to be taken to ensure that the bioreactor design will be able to effectively transport cells and oxygen to all parts of the structure. 


\subsection{Dealing With Limitations of Current TE Techniques}

While traditional tissue engineering has produced positive results in generating tissue, several disadvantages limit its full potential. First, cell distribution is often not uniform. With traditional seeding, a uniform distribution is necessary to ensure homogeneity across the entire construct. Without this proper uniformity, a part of the tissue construct may not differentiate or function correctly because it did not receive a specific cell. On a similar note, while the need for a uniform distribution is important, current techniques cannot easily place different cell types into specific locations on the scaffold [6]. Spatial distribution is important for proper intercellular communication. For example, functions such as wound healing and homeostasis require interactions with neighboring cells. Because current techniques cannot specifically place cells, the adhered cells will need to migrate to their proper locations. The time for these cells to migrate can as long as several months, which could eliminate critical patients from receiving vital tissues.

While the issues listed above are all mainly due to cell seeding techniques, scaffolds used in traditional tissue engineering also suffer from limitations. For example, PLA scaffolds have characteristically rigid structures. While this scaffold would be appropriate for tissues like bone, tendons, and ligaments [70, 12], this rigidity would not be appropriate for contractile tissues, such as cardiac tissue. Furthermore, traditional scaffold fabrication methods, such as casting and molding, often produce tissues that lack vascularization. Vascularization is a vital characteristic if larger tissues are to be constructed [6]. While most researchers are working to resolve these problems to 
continue using traditional techniques, some researchers are looking towards other techniques and technology to bypass these issues.

By including the cell depositing process with the scaffold creation process, this project aims to move task of cell seeding away from the bioreactor and accomplish the task during fabrication. Seeding the cells during scaffold fabrication should reduce problems with cell distribution, as the cells would be placed in its proper location before the scaffold is complete. Because of this, the need for cell migration should be reduced, leading to faster culture times. Although no longer responsible for seeding cells, a bioreactor would still be needed with a cell printer. However, a static culture would no longer be appropriate for a printed-cell scaffold, as this method was used to seed cells. Spinner-flask, rotating-wall and perfusion bioreactors could still be used to impart physical and chemical forces to facilitate with tissue growth. 


\subsection{RAPID PROTOTYPING IN TISSUE ENGINEERING}

Prior to the advent of computers, designs were visualized by creating scale models. This often was a time consuming process, and only provided a visual representation of the design. The computer somewhat alleviated this problem by allowing for quick 3D visualization of a design. While this satisfied many architects, engineers also wanted a way to quickly create a physical model that could simulate or fulfill the physical function of their design. Methods of fabricating models, such as casting, molding, and milling, were often slow and required expensive materials. Rapid prototyping provided engineers and architects a relatively cheap and quick way to fabricate models for visualization and functional verification.

Despite its origins in architectural modeling, rapid prototyping technology has begun to provide tissue engineers with a number of potential solutions for problems encountered when trying to create larger, more complex tissues. The most significant issue that rapid prototyping tried to resolve was the issue of vascularization. Nutrients needed to reach every part of the growing tissue, otherwise necrosis occured. To accomplish this diffusion, a complex internal vascular network was required. This network can only be achieved by directing tissue growth with the scaffold. Traditional molding techniques could not build complex porous networks because the mold would be embedded in the interconnecting network. Casting techniques, while somewhat able to integrate the pores, required a lot of time and material to fabricate the casts. Rapid prototyping systems, on the other hand, built models layer-by-layer. This difference allowed for the complex internal pore network to be easily constructed. Furthermore, the 
build-on-demand nature of rapid prototyping provided researchers the potential to easily create custom architectures, based on a patient's own needs.

Related to the issue of nutrient supply, optimized tissue growth is a function that can be potentially aided by using rapid prototyping techniques. Traditional tissue engineering techniques relied on random placement of cells and cell migration in order to generate tissue. To accomplish this task, a tissue scaffold was usually placed in a bioreactor to seed the cells. While sufficient for seeding single cell-types, this technique may not be efficient when trying to engineer multi-cellular tissue, as similar cell types usually group together in tissues. Although tissue has been engineered using this technique, researchers could experience difficulty when trying to grow larger tissue. With larger constructs, cells may have a harder time diffusing deep within the complex network, leading to an improper distribution of cells. Because rapid prototyping systems build a structure layer-by-layer, cells could be strategically integrated into a scaffold as it is being fabricated. This on-demand characteristic could allow for 3D-specific placement of cells, reducing the need for cells to migrate to its desired location on a scaffold.

Depending on the complexity of the RP system, multiple cell-types could be strategically placed for optimal tissue growth.

Currently in the rapid prototyping market, over sixteen RP systems are available. For tissue engineers, however, at least six of these systems have been investigated for use with tissue engineering applications. While all six of these systems utilize a layer-based construction model, they implement this 3D construction using different methodologies. In this paper, these systems will be classified into two primary categories: 3D dispensing systems and particle-bonding systems. 


\subsection{D Dispensing Systems}

Three-dimensional (3D) dispensing systems are a class of rapid prototyping devices that primarily extrude a semisolid material. Following extrusion, this material eventually hardens and binds to the previous layer. Successive layers are then extruded, allowing for the formation of a $3 \mathrm{D}$ object. The ability of the extruded material alone to support itself when constructing 3D structures is this system's primary advantage.

\subsubsection{Direct Inkjet Printing}

Despite its name, direct inkjet printing can be considered more as a melt deposition system. A direct inkjet, available through companies such as 3D Systems, dispenses fluid in a discontinuous fashion, much like a traditional inkjet printer. Because the system does not rely on a continuous stream of fluid, multiple nozzles and heads can be used. Unlike standard inkjet printers, however, direct inkjet printers utilize a wax-like thermoplastic material as the "ink." Therefore, like fused deposition modeling, the dispensed material hardens, allowing successive layers to be built on top of itself.

This technology has not been extensively utilized in tissue engineering applications for a few reasons. First, material choices were severely limited with direct inkjet printers. The polymers used with 3D Systems' implementation of the technology, for example, have not been tested for biocompatibility. Second, heat generated by the system may be harmful to the cells. A constant temperature must be maintained to maintain the thermoplastic material in a semi-fluidic phase. Temperatures exceeding $37^{\circ} \mathrm{C}$ could put the cells at risk of dying; to contrast, some direct inkjet waxes have melt temperatures exceeding $100^{\circ} \mathrm{C}$ [35]. Finally, models built using this technique require 
support structures, usually made of waxes of different solubility than the main material. Because of this characteristic, extra processing is required to eliminate the supports, making it not only difficult to create the complex internal structure, but also nearly impossible for simultaneous cell-seeding. Because of these limitations, direct inkjet printing has been relegated primarily to creating molds for casting with bioactive polymers [45].

\subsubsection{Fused Deposition Modeling (FDM)}

The most common variation of a melt deposition system is fused deposition modeling (FDM). This technology, commercially available through companies like Stratasys, utilizes a continuous flow of material. In a typical FDM system, a polymer monofilament is fed into the extrusion head. A heater within the head melts this monofilament into a viscous semisolid. The melted thermoplastic is then extruded through the head's nozzle onto the build platform or previously deposited layer. To allow for binding of successive layers to form a solid, the entire build platform is enclosed within a heated, temperature-controlled cabinet.

Due to the continuous flow of the polymer, FDM systems typically operate using vector-based operations. Each consecutive layer, as well as each deposited material, can be deposited in a different direction and gap spacing. By controlling these two factors, a complex, honeycomb-like internal structure can be formed. Furthermore, the ability to change the direction of successive layers can strengthen the structure. The zigzag pattern to create a solid layer can act much like a layer of fiber, able to resist forces in only one 
direction. By changing the direction of each additional layer, the structure becomes more able to resist forces in other directions.

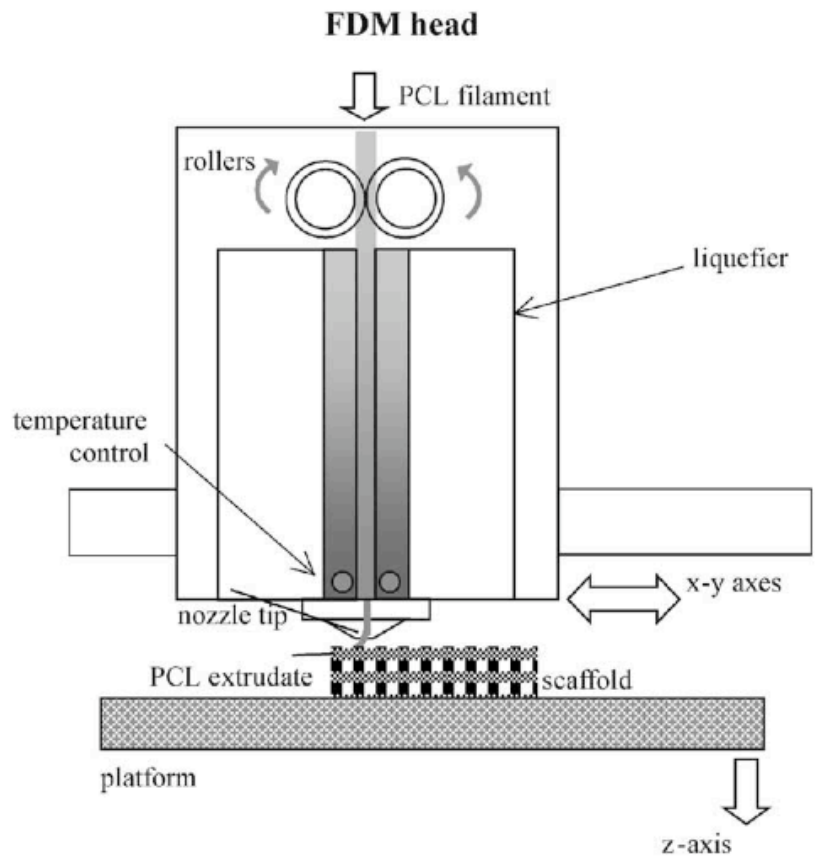

Figure 3.1 Schematic diagram of a typical FDM system [72]

A few issues limit this technology's use in tissue engineering. First, although the system allows for variable pores, it cannot create consistent pores in all three dimensions. As material overlaps in consecutive layers, pores in the xy-plane can become partially occluded. Second, while the dispensed polymer alone can achieve material buildup, support structures are still required to ensure the integrity of the model [4]. However, compared to direct inkjet printers, not as much support material is required. As a result, a complex internal structure is still possible. This possibility allowed researchers like Zein et al. to fabricate poly(caprolactone) scaffolds, which could have been used with hard tissue cells, such as osteoblasts [72]. Unfortunately, other desired functions, such as the 
ability to fabricate soft tissue scaffolds and simultaneous cell integration, are more difficult to achieve for a few reasons. First, solvents are required to free the construct from its support. These solvents are often toxic to cells. Second, the materials need to be pre-processed into a filament, which could make the process of integrating cells difficult. In addition, the low water content required to create a filament means that hydrogels, which are commonly used to support soft tissue cells, cannot be fabricated using FDM. Finally, just like direct inkjet printing, the dispensed material relies on heat to melt the material. Although Zein et al. were able to use a biocompatible material like poly(caprolactone), they would not have been able to simultaneously integrate cells using the FDM system, as the material had a melt temperature of $60^{\circ} \mathrm{C}$ [72].

\subsubsection{D Bioplotting}

Recently, researchers have been investigating whether a newly developed form of 3D dispensing could resolve a couple of issues with the previous 3D dispensing systems discussed. Like the other dispensing systems, a 3D bioplotting system dispenses a viscous fluid. However, unlike the solid platform that is used by these other systems, 3D bioplotters dispense into a liquid medium. This medium, which must match the density of the dispensed material, provides a neutral buoyancy effect for the model being constructed [45]. As a result of the force reduction on the model, the need for support structures is eliminated. This elimination therefore allows for the construction of a variable internal pore network, much more complex than what is achievable by FDM.

3D bioplotting also reduces the problem of materials. Other 3D dispensing systems, like FDM or direct inkjet printing, are severely restricted in materials options. 
FDM systems, for example, cannot process many biodegradable polymers due to its very narrow processing window; currently, poly(caprolactone) (PCL) is the only known degradable polymer that works with FDM [45]. Because of the nature of 3D

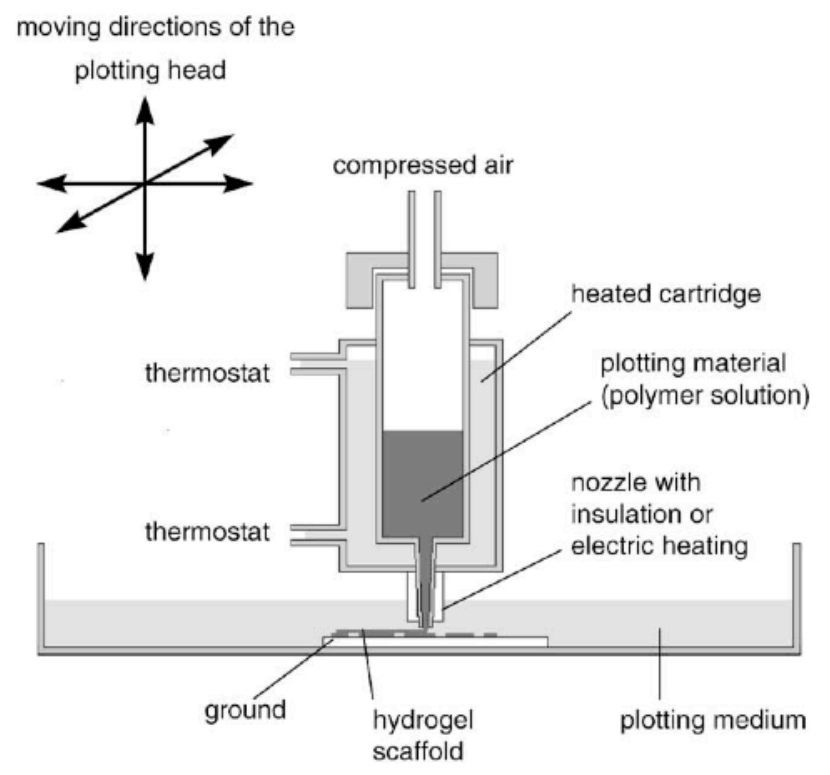

Figure 3.2 Schematic drawing of a typical 3D bioplotter [31]

bioplotters, a wide variety of materials, including polymers such as PLGA and PCL, thermoset resins, and even cement, have been shown to be compatible with the system. For instance, a study by Rücker et al. created a PLGA scaffold with a 3D bioplotter [48]. In their study, the bioplotted PLGA scaffold elicited a weak immune response and showed signs of vascularization after implantation. Furthermore, because of its aqueous build environment, bioactive materials, such as proteins, have also been used with 3D bioplotters [45]. For example, in addition to the PLGA scaffold discussed above, Rücker et al. used the same 3D bioplotting system to fabricate a scaffold containing collagen, chitosan, and hydroxyapatite [48]. 


\subsection{Particle-Bonding Systems}

As its name implies, this RP technology bonds or fuses selected particles in order to form a solid. Unlike 3D dispensing systems, which dispense the build material onto an empty platform, particle bonding systems start with the build material already on the build platform. Although present on the build platform, this material is unprocessed and unbound. A head then passes over the material to bind material in a desired pattern. Following completion of the layer, a fresh layer of unbound material is placed over the bound material, and the process repeats.

This RP technique shares similar advantages with 3D bioplotting. Like 3D bioplotting, the structure is surrounded by a supporting medium. However, rather than using a support material that differs from the build material, particle-bonding systems use a single material that serves as both build material and support. As the structure is built in a particle bonding system, the surrounding unbound material continuously supports it. Therefore, like 3D bioplotters, structures built with particle bonding systems do not require additional support structures. Also due to the lack of support structures, particlebonding systems are capable of creating complex internal structures.

Three of the most common particle-bonding systems are defined below.

However, stereolithography is technically not considered to be a particle-bonding system because of the material choice. Because it shares many of the same fundamentals as a traditional particle-bonding system, it will be included in this category. While all these systems share the same advantages described above, they each have their own unique advantages and disadvantages as well. 


\subsubsection{Stereolithography}

Stereolithography (SLA) is a liquid-based system that shares some characteristics of a traditional particle-bonding system. Typical SLA systems, available from companies such as 3D Systems, house a photo-curable resin in the build space. To form a solid, the submergible build platform is first raised until only a very thin layer of fluid covers the platform. A mobile mirror then directs a UV laser onto the fluid. Any fluid exposed to this UV laser would undergo photo-polymerization, causing a solid to form. Upon completion of the layer, the elevator drops the structure enough to cover the cured layer with a fresh coat of liquid resin, and the process repeats.

While this method shares a number of the same advantages as a 3D bioplotter, it has a serious disadvantage, especially with respect to tissue engineering applications. A 3D bioplotter is compatible with a wide variety of materials, ranging from melts, solutions, reactive resins, paste, cements, and biologic materials. SLA systems, on the other hand, are severely limited in material options. Current SLA devices are currently restricted to photo-reactive resins. Furthermore, the available resins are all toxic. Despite these disadvantages, SLA has been used for scaffold production. In one study by Chu et al., a lost-mold process was developed around SLA [29]. In their study, the standard, commercial epoxy resin was used. Rather than fabricate the scaffold directly, the SLA system was used to fabricate a negative mold of the intended scaffold design. An organic suspension, which consisted of hydroxyapatite and acrylic binders, was then cast into the mold and cured. This solid then underwent pyrolysis and sintering to remove the epoxy and acrylate, as well as strengthen the scaffold; the group did note, however, that a miniscule amount of binder did remain after the procedure. After all this 
post-processing, the group was able to obtain a scaffold with channels as fine as $366-\mu \mathrm{m}$, very close to the $250-\mu \mathrm{m}$ lower limit of the UV laser [29]. Subsequent research by the group showed that their scaffold had an elastic response similar to coralline hydroxyapatite. Furthermore, in-vivo testing demonstrated that osteogenesis was taking place within the scaffold [9]. Although some binder material does remain, Chu et al.'s work did demonstrate the possibility of using SLA for bone scaffold research.

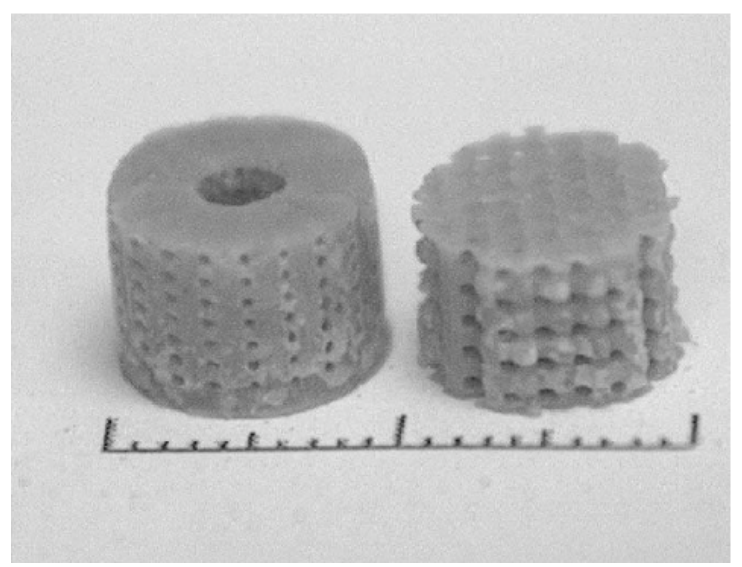

Figure 3.3 Hydroxyapatite scaffolds built using SLA technology [10]

\subsubsection{Selective Laser Sintering}

Selective Laser Sintering (SLS) is a traditional particle-bonding system that utilizes a $\mathrm{CO}_{2}$ laser beam [4]. Unlike SLA systems, SLS systems house a bed of unbound powder. An elevator platform is raised to the top of the powder bed, and a roller ensures that a flat layer of powder resides at the top. To form a solid, a deflected laser beam selectively scans over the desired location. The laser beam causes the powder's temperature to rise to its glass-transition point, causing it to fuse with neighboring particles. Following completion of the layer, the platform descends slightly, the roller dispenses a new layer of powder over the completed layer, and the process repeats. 
SLS technology has its own unique characteristics. Because the particles are fused together, structures created using this method can withstand greater forces than other structures. Many SLS systems also allow the end-user to fine tune the microstructure. By controlling the laser's exposure density, scan speed, and temperature, the quality of sintering can be adjusted. Because binding is achieved by the use of the laser's energy, additional solvents are not required. However, this RP method also has a few limitations. Like SLA, SLS systems have limited material options. The minimum pore size also depends on the powder's particle size, which is usually around $50 \mu \mathrm{m}$ in diameter [4]. Because of the high temperatures involved when using the laser, the system is restricted mainly to thermally stable polymers. This high temperature also eliminates the possibility of simultaneously depositing cells.

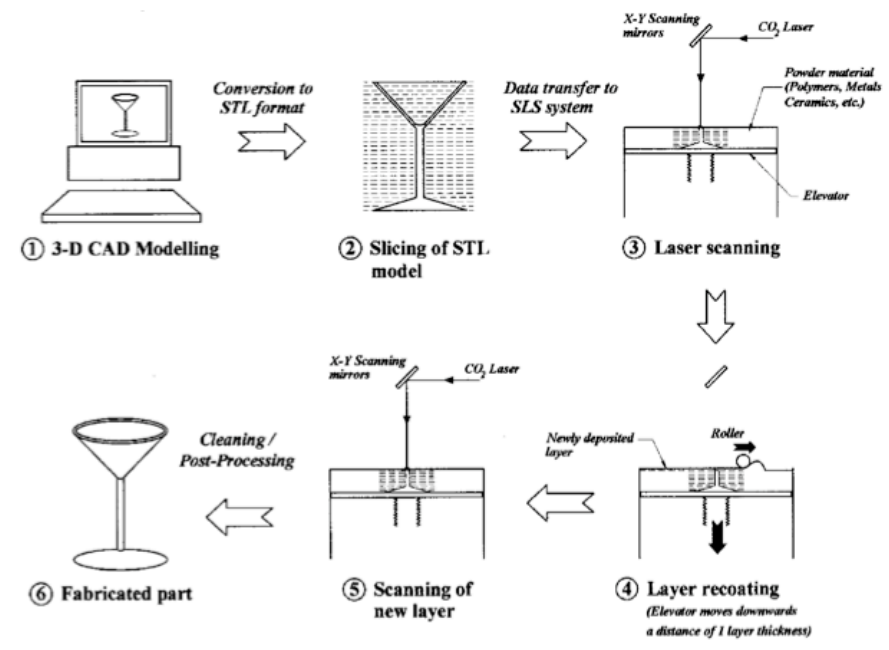

Figure 3.4 Schematic diagram of SLS workflow [55]

Although the system was not capable of depositing cells, SLS was still used in tissue engineering research. Its use, however, was mainly restricted for creating scaffolds. In particular, researchers investigated whether the technology could be used to 
develop bio-ceramic scaffolds for use in repairing bone defects [55]. In one study, hydroxyapatite particles were coated in poly(methylmethacrylate), which served as the primary binding particle [33]. Unfortunately, this procedure involved the use of an organic solvent, which was undesirable for tissue engineering. However, it did demonstrate that a biomaterial could be successfully integrated into a scaffold created using SLS. Another study eliminated the need for solvents by using a powder blend consisting of hydroxyapatite and polyetheretherketone (PEEK). PEEK was a thermostable polymer that exhibited a low amount of cytotoxicity [55]. This study demonstrated that SLS, like SLA, could be used in bone tissue engineering applications.

\subsubsection{D Printing}

Not to be confused with direct inkjet printing, three-dimensional printing (3DP), developed in 1989 at the Massachusetts Institute of Technology [4], is a powder-based particle-bonding system that involves the use of inkjet heads [45]. Like SLS systems, a 3D printer utilizes a roller to spread and compact powder over a descending build platform to create a thin powder layer. Typical 3D printers, available from companies like Z Corp, use a starch-based powder. However, instead of using a laser to fuse particles together, 3DP employs inkjets to bind particles. The inkjet cartridges, most often taken from commercial desktop printers, are loaded with an aqueous binder solution, and then dispense ink over selected areas to bind the powder. Once a layer has been exposed to the binder fluid, the roller spreads another layer of powder, and the process repeats. 

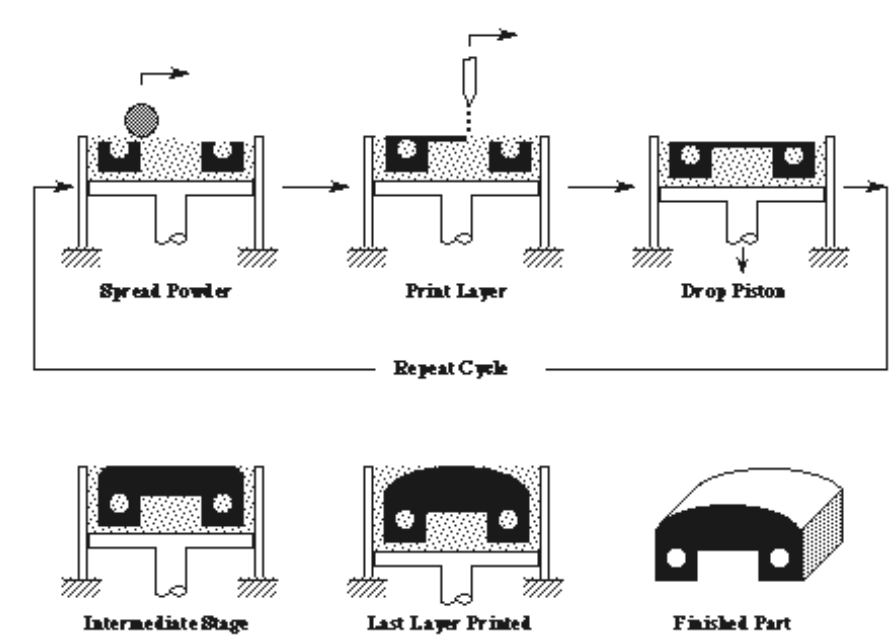

Figure 3.5 Schematic diagram of 3DP workflow [25]

Of all the particle-binding systems, 3DP offers the most flexibility for materials. Looking at the previously mentioned systems, SLA can only use reactive, toxic resins; SLS is slightly more flexible, being restricted to thermostable polymers. 3DP, on the other hand, can use materials based on starch, sugars, polymers, plaster, metals, and even ceramics [45]. A caveat of this flexibility is that these materials must be available in powder form. Like SLS materials, the resolution and porosity of a 3DP-created structure is heavily dependent on the powder's particle size. On average, a 3DP system is able to achieve a $300-\mu \mathrm{m}$ resolution, with pore sizes in the range of $45-150 \mu \mathrm{m}$ in diameter [69]. While this places the porosity achievable with 3DP on the same level as SLS, it falls short of the larger 250-1000 $\mu \mathrm{m}$ pores that can be created using 3D dispensing technologies, such as FDM [4].

3DP does have its own set of problems. One disadvantage of 3DP is that solvents often are used with the system. Usually, organic, though toxic, solvents serve as the binder. In addition to this disadvantage, extra post-processing is required to strengthen the structure after printing, which often also involves toxic substances. This need for 
toxic chemicals, however, was not always the case. In one study, for example, Lam et al. were able to develop a starch-based powder that was able to be bound using just distilled water [69]. Compared to other organic solvents, distilled water was much more biocompatible. This study served as a perfect example of the flexibility that the RP method offered, even with the binder solution.

Because of its great flexibility and relative low operating costs, 3DP has been extensively used in tissue engineering, especially in scaffold creation. In the previous example, Lam et al. not only developed a more biocompatible powder/binder combination, but also successfully created scaffolds using their materials [29]. To further the strength of the scaffold while maintaining biocompatibility, the group infiltrated the scaffold with a PLLA and PCL copolymer. The group observed a maximum of $12 \%$ shrinkage following post-processing, with circular pores causing the greatest reduction. Not surprisingly, scaffolds infiltrated with a higher volume of copolymer were shown to exhibit more water resistance and stiffness.

In addition to using standard 3DP techniques, Tay et al. demonstrated how a unique step in their workflow aided scaffold creation. In their study, PCL and poly(vinyl alcohol) (PVA) powders, mixed in various proportions, were used as the powder bed. Interestingly enough, PVA, this time in a liquid state, also served as the binder. In the post-processing step, the scaffold was immersed in de-ionized water. PVA, a watersoluble particulate, leeched out when immersed in de-ionized water [56]. As a limitation of this method, the scaffold needed to be heat-treated at $65^{\circ} \mathrm{C}$ in order to ensure that the scaffold could maintain integrity when immersed for some time [56]. While the heat 
treatment made simultaneous cell seeding impossible, this unique process demonstrated a novel method of creating the complex pore network needed in scaffolds.

Kim et al. showed how viable printed scaffolds were with cells [25]. In their study, PLGA powder was combined with sodium chloride particles to serve as the powder bed. They fabricated a cylindrical construct with interconnected longitudinal and radial channels. In a technique similar to Tay et al., the salt particles were leeched out using distilled water, facilitating the creation of the interconnected channels. Following this salt leeching, the scaffold was then soaked in culture medium, statically seeded with hepatocytes, and finally perfused in a bioreactor. Their tests showed successful attachment and migration of the hepatocytes. Lam, Kim, and Tay's results demonstrated that 3DP technology could be a potentially be adapted for tissue engineering.

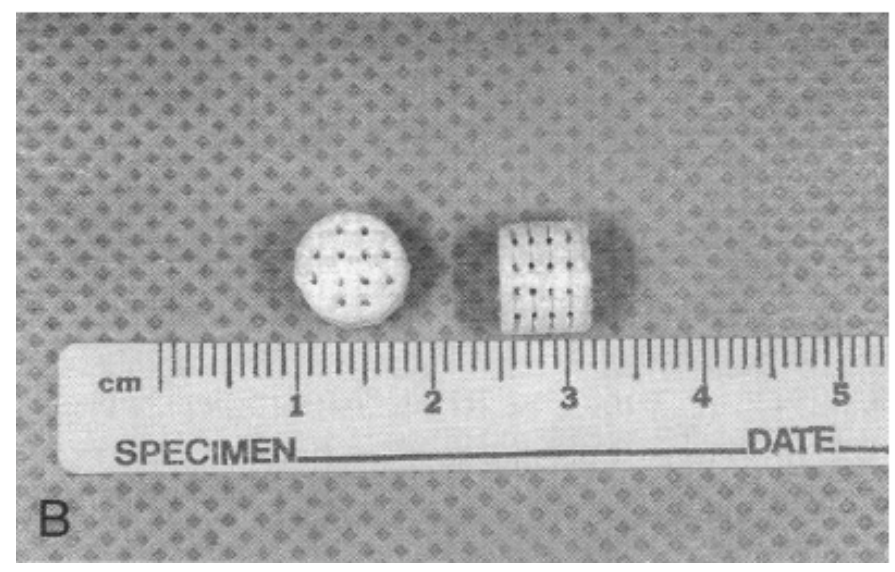

Figure 3.6 Scaffolds created using 3DP and salt leaching [25]

\subsection{Choosing the Most Appropriate RP System}

Almost all of the systems described above have been used for some application of tissue engineering. In terms of scaffolds, everything but direct inkjet printing could have 
been used. However, when considering the future ability to fabricate a biocompatible scaffold using the same device, SLA became less appropriate due to the toxic resins used. Since cells were going to be dispensed with this system, the dispensing system had to be "gentle" to the cells. Some ideal characteristics to achieve this function included a low operating temperature and easy integration of cells with the system. These requirements eliminated FDM because of the processing required for the printing materials, as well as the heating element to melt the thermoplastics. SLS was also eliminated because of its high-energy output required to fuse the substrate. After considering all these requirements, only 3DP and 3D bioplotting were left as viable options.

While both systems featured a substrate-supported build model, the technology behind 3DP was chosen for this project for a few reasons. First, the department already had access to a Z-Corp 3DP system, so it could be used as reference for adding scaffold fabrication abilities to the system in the future. In terms of materials, a 3DP potentially worked with a greater set of materials, compared to 3D bioplotting. 3D bioplotters required the substrate to match the density of the printed solution. A 3DP, on the other hand, required that the powder bind with the printed solution. Finally, since the surrounding environment consists of air, a 3DP inkjet did not require a complex setup; in comparison, a 3D bioplotter could have required the use of a needle and higher pressures in order to dispense into the fluidic environment. Although the system could easily be adapted for 3D bioplotting functionality, a 3DP-like approach was chosen for simplicity. 


\subsection{INKJET TECHNOLOGY AND ITS ROLE IN CELL PATTERNING}

The rise of rapid prototyping has initiated research into using various techniques to generate the complex 3D models. Inkjet technology, currently used in 3D Printing, offers a number of advantages in rapid prototyping. It is widely used due to its low cost and high availability. Furthermore, its simplicity leads to lower production costs. The ability to use virtually any fluid allows for great flexibility in materials selection.

Because of the abundance of tissue engineering research using this technology, as well as the simplicity involved in its use, an inkjet-based system was investigated in this project. Utilizing this technology for scaffold development and cell deposition, however, requires further study of the various types of inkjets and their characteristics. Therefore, this chapter will provide an overview of the various forms of inkjet technologies that have been considered for tissue engineering applications.

\subsection{Continuous Inkjet Technology}

Continuous inkjets are one major classification of inkjet technology that is still used today. This form of ink jetting dateed back to 1878, when Lord Raleigh first described the method to break streams into a series of droplets [46]. This technology utilizes a high-pressure pump to rapidly propel fluid from a reservoir through a tiny orifice, creating a high-velocity, continuous flow of fluid. A piezoelectric crystal then oscillates within the nozzle to create a pressure wave pattern, which disperses the continuous stream of fluid into droplets. To control its direction, the droplets pass through an electrode, charging the droplets. Deflection plates then direct the charged droplets either to the print surface or to a collection gutter for recycling. 


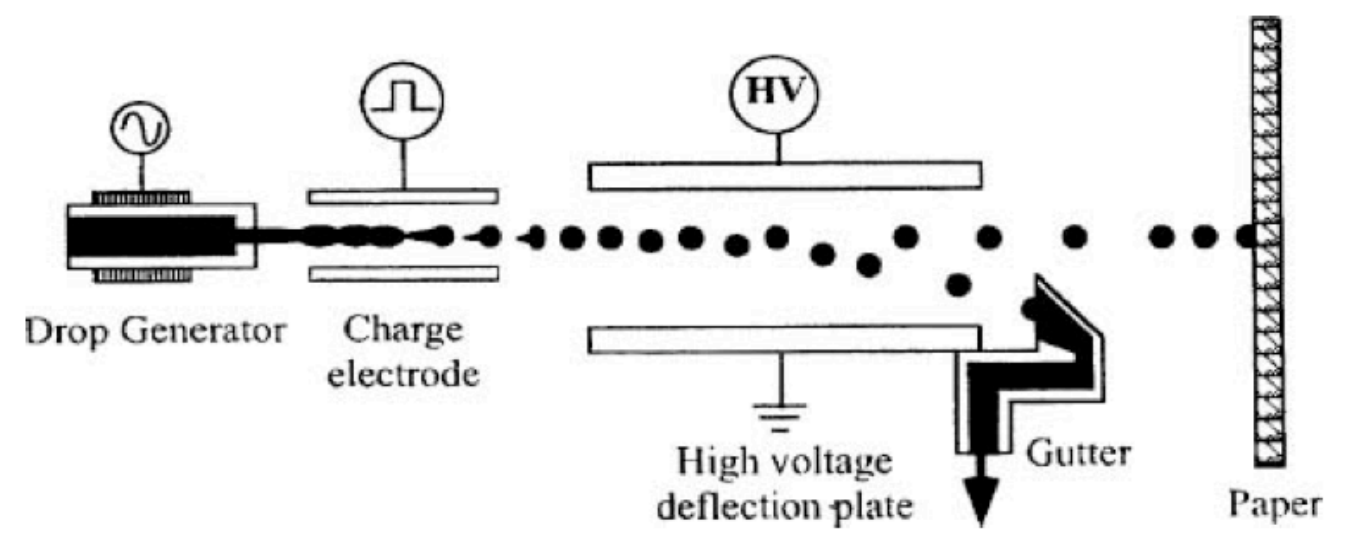

Figure 4.1 Schematic illustration of binary-deflection continuous ink jet [32]

While continuous inkjet technology could have allowed for rapid deposits of fluid, a couple characteristics of this technology made the system unfeasible for handling cells. The primary problem with continuous inkjets was the constant exposure of the fluid to the environment. This constant fluid flow could have potentially resulted in contamination if the print environment was not adequately sterilized. Another issue with the system was potentially low accuracy. With a continuous inkjet, the placement of the droplet relied solely on how well the electromagnetic plates deflected the fluid. Performing this deflection would have required a complex hardware setup. To reach micron-level accuracy, even more complex hardware could have been required. The nature of the droplet position could also have been affected by the molecular properties of each individual droplet. Droplets that were charged differently could have reacted in different ways to the deflection plates. Therefore, consistency between droplets would have become an issue. 


\subsection{Drop-on-Demand Inkjets}

The other major classification of inkjet technology is known as drop-on-demand (DoD) inkjet technology. Unlike continuous inkjet technology, which has a constant fluid flow into a reservoir until deflected onto the print surface, drop-on-demand inkjets dispense drops only when required. This difference results in fewer complex components required to operate. However, because an individual nozzle can only dispense a single drop at a time, many nozzles are required to reach the same rate of fluid flow as a continuous inkjet.

When considering applications in cell depositing, DoD inkjets should be the more appropriate choice of technology. As previously mentioned, continuous inkjets would have constantly exposed all the fluid to the print environment. Because drops in a DoD inkjet dispense on demand, only the fluid that comes in contact with the print surface would be exposed to the atmosphere. As a result of this difference, the risk of contamination should be significantly reduced. Furthermore, DoD inkjets should be more accurate. Unlike continuous inkjets, DoD inkjets only dispense fluid directly below the nozzle. This limited range of direction would reduce complexity in achieving highresolution patterns, currently as accurate as $350-\mu \mathrm{m}$ [47]. This accuracy would only be limited by how precise the positioning motors could move and how small of a droplet the inkjet could form.

Two types of drop-on-demand inkjet technology are commonly used today. Both dispense fluid by the drop, but perform this task using different methodologies. A third technology, which was used for this project, operated on a completely different set of 
principles. However, due to similar characteristics with the more common forms of inkjets, this third form was also classified as an inkjet.

\subsubsection{Thermal Inkjets}

The first of these drop-on-demand implementations is a thermal inkjet, not to be confused with thermal wax inkjets (dye sublimation). This system, first commercialized by Hewlett Packard in the 1970s, utilizes heat to eject fluid from its head. Fluid is first loaded into a chamber in the inkjet head. A thin resistor then heats up a small amount of the fluid (less than $0.5 \%$ ) until a gas bubble is formed [5]. This bubble then expands until a drop is forced out of the nozzle. New fluid fills in the chamber, and the process repeats. Two main variations of this system currently exist. One version, called a roof-shooter, places the heater element above the orifice. A side shooter, on the other hand, places the orifice along the side, with the heating element along part of the wall [32].
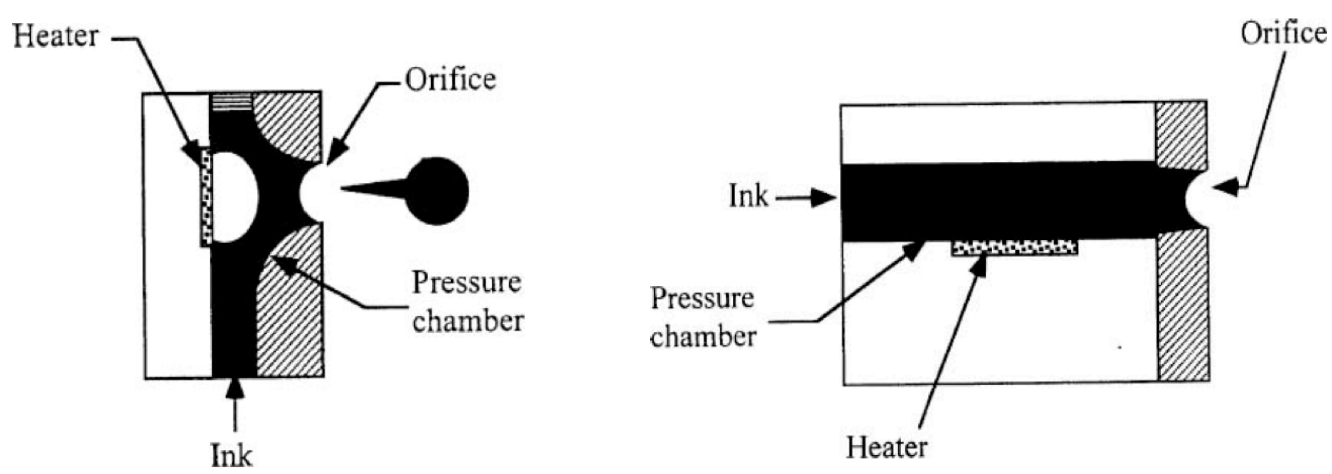

Figure 4.0 Schematic diagram of (a) roof-shooter and (b) side-shooter thermal inkjets [32]

Thermal inkjets have been used to dispense proteins. A study by Roth et al. used a collagen solution with an old Canon thermal inkjet [47]. In their study, a glass coverslip was coated with agarose, which functioned as the substrate. The thermal inkjet then printed the collagen in various patterns on the substrate. Following printing, the 
coverslip was placed in a well and seeded with neuronal cells and smooth muscle cells and incubated for a number of days. Initial observations, performed by light microscopy, showed a number of unattached cells. However, by the fifth day of incubation, cells that did adhere in the printed pattern began to reach confluency. Interestingly enough, the group noted that higher densities of cells when seeding resulted in a shorter lifespan for the attached cells; lower densities, on the other hand, lasted longer, but also took longer to reach confluency. These results demonstrated that ECM components could potentially be used with thermal inkjets.

Thermal inkjets have also been used to deposit a variety of actual cells. Xu et al. attempted to deposit ovary and neuromuscular cells [68]. This study reversed the ink and substrate that were used by Roth et al. in the previous study. In Xu's study, ovary and motoneuron cells were loaded into a standard HP cartridge and inkjet printer, while agar and collagen were pre-coated onto a glass coverslip to serve as the substrate. Following printing of the different cells, the coverslip was incubated in culture medium. Like with Roth's results, many cells were observed to be undifferentiated or dead after one day of incubation, but the remaining cells were able to show signs of proliferation after several days. The motoneuron cells, in fact, showed signs of differentiation after only 5 days in culture. Both Roth and Xu's successes demonstrated that thermal printing was a viable option for inkjet-based tissue engineering.

\subsubsection{Piezoelectric Inkjets}

Canon and Epson currently use the other major drop-on-demand technology, known as piezoelectric (piezo) inkjets. Unlike thermal inkjets, piezo inkjets do not use 
heat to dispense droplets. In a typical piezo print head, one side of the fluid chamber contains a diaphragm. This bendable diaphragm is connected to a piezoelectric ceramic [32]. Once the chamber is loaded with fluid, an electric charge is applied to the piezo ceramic. This charge causes the piezo ceramic to change its conformation, resulting in a volume decrease inside the fluid-filled chamber. By decreasing the chamber volume, the chamber pressure increases, causing the fluid in the chamber to flow out of the one-way nozzle.
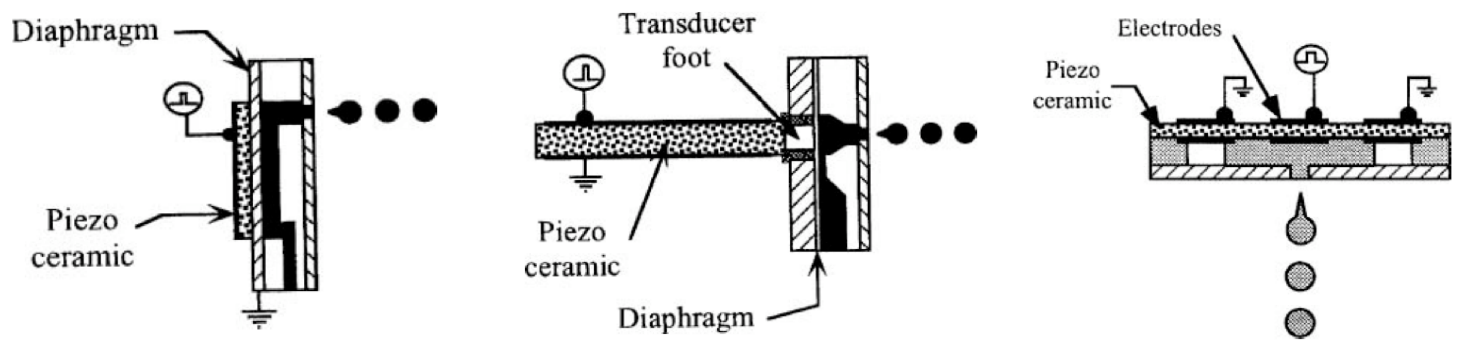

Figure 4.2 Schematic illustration of (a) bend-mode, (b) push-mode, (c) shear-mode piezo inkjet [32]

Three variations of this form of drop-on-demand inkjet technology exist; however, these varieties operate on the same principle of volumetric changes to dispense fluid. In a bend-mode piezo ink-jet, as shown in Figure 4.2a, the piezo ceramic, diaphragm, and fluid chamber are aligned in a laminar fashion. An electric charge, applied parallel to the polarization of the ceramic, causes the material to bend towards the chamber. This action forces the diaphragm inward as well, decreasing the chamber's volume. A push-mode piezo inkjet (Figure 4.2b) operates in a similar fashion. However, in this variation, the piezo ceramic is in the form of a rod, where one end of the rod is attached to the diaphragm. The applied charge causes the rod to expand, pushing into the diaphragm, causing fluid ejection. Unlike the previous two variations, a shear-mode 
piezo inkjet (Figure 4.2c) contains no diaphragm. Instead, the piezo ceramic itself forms an active wall that comes in contact with the fluid. Electric fields, this time perpendicular to the piezo ceramic's polarization, cause the material to shear, deforming against the chamber [32].

Researchers have investigated whether piezoelectric inkjets could be used for printing human cells. Saunders et al. tested human fibroblasts with a single piezo inkjet, rather than a commercial inkjet system [51]. Unlike the studies performed by Roth and $\mathrm{Xu}$, Saunders did not use any pre-fabricated substrate; instead, the cells were directly printed into uncoated well plates. To analyze the effects of changes to the printing process, Saunders also varied some controllable conditions, such as excitation voltage and rise time. A doubling in voltage resulted in cell viability dropping from $98 \%$ to $94 \%$. The group could not find any statistical significance in changes to the voltage rise time, however. Despite the slight decrease in cell viability, Saunders et al. demonstrated that piezo inkjets could be used to safely deposit cells.

Another study, following earlier research by Sanjana et al. [49], attempted to use a custom-designed piezoelectric dispenser with neural cells. In Gustavsson et al.'s study, cells from mouse dorsal root ganglia were fed through a proprietary microdispenser [19]. This microdispenser, modeled after a push-mode piezoelectric jet, was claimed to dispense drops with 6-8 $\mu \mathrm{m}$ of precision. In addition to testing the inkjet design, the study also included variations to platform warming, solution density, and print surface. The group observed that patterning on glass cover slips was more difficult than printing on plastic culture plates, due to frequent droplet aggregation on the cover slips. To compare the effect of temperature on the cells, the group integrated a $30^{\circ} \mathrm{C}$ heater on the 
platform. When using the heater, lines printed ended up fairly smooth; non-heated lines, on the other hand, appeared ragged, due to spreading of the solution. When the densities of both the neurite solution and a bovine serum albumin (BSA)/laminin solution were varied, the group noted that a solution with increased density printed out as a thin line, due to an increased viscosity. Neurite growth was shown to follow the printed pattern at this high density. With lower densities, the lines of printed solution came out thicker due to the lower viscosity; neurites in this scenario did not follow the pattern of BSA/laminin. Gustavsson et al. successfully demonstrated that a piezo dispenser could not only dispense neural cells, but also direct their growth.

\subsubsection{Solenoid-based Inkjets}

Solenoids have been utilized for more industrial inkjet designs. This form of inkjet technology operates in a different fashion than traditional inkjets. In a solenoidbased inkjet printer, such as the one utilized in this project, no sudden physical changes affect the printer fluid to induce droplet dispensing. Instead, a constant pressure provides the driving force behind fluid flow. This gradient could be established in different ways. For example, ink could be loaded into a syringe-like reservoir and become pressurized by physically moving a plunger. Unlike a piezo print head, the pressure gradient in a solenoid-based inkjet is continuously applied throughout the entire ink reservoir. To dispense a drop, a current is quickly pulsed through the solenoid valve. As the current passes through the solenoid, a magnetic field is induced. A plunger, normally keeping the valve closed, moves toward this magnetic field, thus opening the valve. Once the valve is open, the previously established pressure gradient forces fluid to eject out. 
These solenoid-based inkjets, available through companies such as The Lee Co., offer a couple of advantages over the thermal inkjets. The main problem with thermal inkjets is the relatively high-temperature, although quick, bursts experienced by the printer fluid to induce bubble formation. While no adverse results have yet to surface, it is possible that more sensitive cells or proteins could be sensitive to these high temperatures. A solenoid-based printer does not need any heating elements to induce droplet formation. As a result, cells could experience less strain through a solenoid-based inkjet. In addition to better cell compatibility, this characteristic could allow for a wider variety of materials to be used with the system, especially thermo-sensitive polymers like collagen.

Few differences exist between impulse and piezoelectric inkjets, however. Both systems operate on the principle of a pressure gradient in the print chamber to induce fluid flow. Piezo inkjets achieve this pressure by physically decreasing the chamber's dimensions in increase pressure. The solenoid valve in an impulse inkjet, on the other hand, uses electromagnets to open its valve, and an already pressurized fluid environment to induce flow. While the piezoelectric system has the disadvantage of slight temperature fluctuations from resistance in the chamber walls, the solenoid system has the disadvantage of having to constantly pressurize the fluid reservoir. Since piezoelectric inkjets have already been shown to work with cells, this project attempted to demonstrate that a solenoid-based inkjet could also be used to safely print cells for tissue engineering applications. 


\subsection{Is a Smaller Droplet Better?}

Apart from the method of droplet formation, one characteristic that also deserved consideration when choosing an inkjet should be the inkjet's droplet size. This factor, which includes the droplet's volume among other things, can heavily affect the resolution of the device. When considering typical uses for a printer, such as printing text or graphics on paper, a tiny resolution is an ideal feature for accurate representation of the element being produced. However, this feature may not be desirable for an inkjet used for this project.

When considering how the inkjet in this project would be used, a tiny droplet size could possibly be a disadvantageous characteristic, rather than an advantage, for the system. For the system to be efficient as well as effective, a single drop would theoretically be dispensed where one would want to place a cell. For this previous statement to be effective, the drop dispensed would have to contain at least one cell. However, the chances for a viable cell to attach could increase if more cells were dispensed in each drop.

In an actual test of the cell printer (explained in the next chapter), a cell concentration of $6.2 \mathrm{E} 4$ cells $/ \mathrm{mL}$ was calculated from measurements. From other tests, the printer was calculated to dispense about $.290 \mu \mathrm{L}$ per drop. Using these values and the relationship

$$
c=\bar{n} / V_{d}
$$

where $\mathrm{c}$ is the average cell concentration of the solution and $V_{d}$ is the volume of the drop,

the average cells per drop, $\bar{n}$, was calculated to be about 17.98 cells. Research performed by Merrin et al. showed that a Poisson distribution could be used to adequately estimate 
the number cells found in a single droplet [37]. Therefore, the probability, $p$, of finding $n$ cells per drop could be estimated as

$$
p_{n}=\frac{\bar{n}^{n} e^{-n}}{n !}
$$

Rounding down the value of $\bar{n}$ previously calculated, the printer theoretically had a 7.04E-5 percent probability of having one cell per drop. Although this probability may sound low, the chances for finding more than one cell per drop are significantly higher, as shown by the blue graph in Figure 4.3.

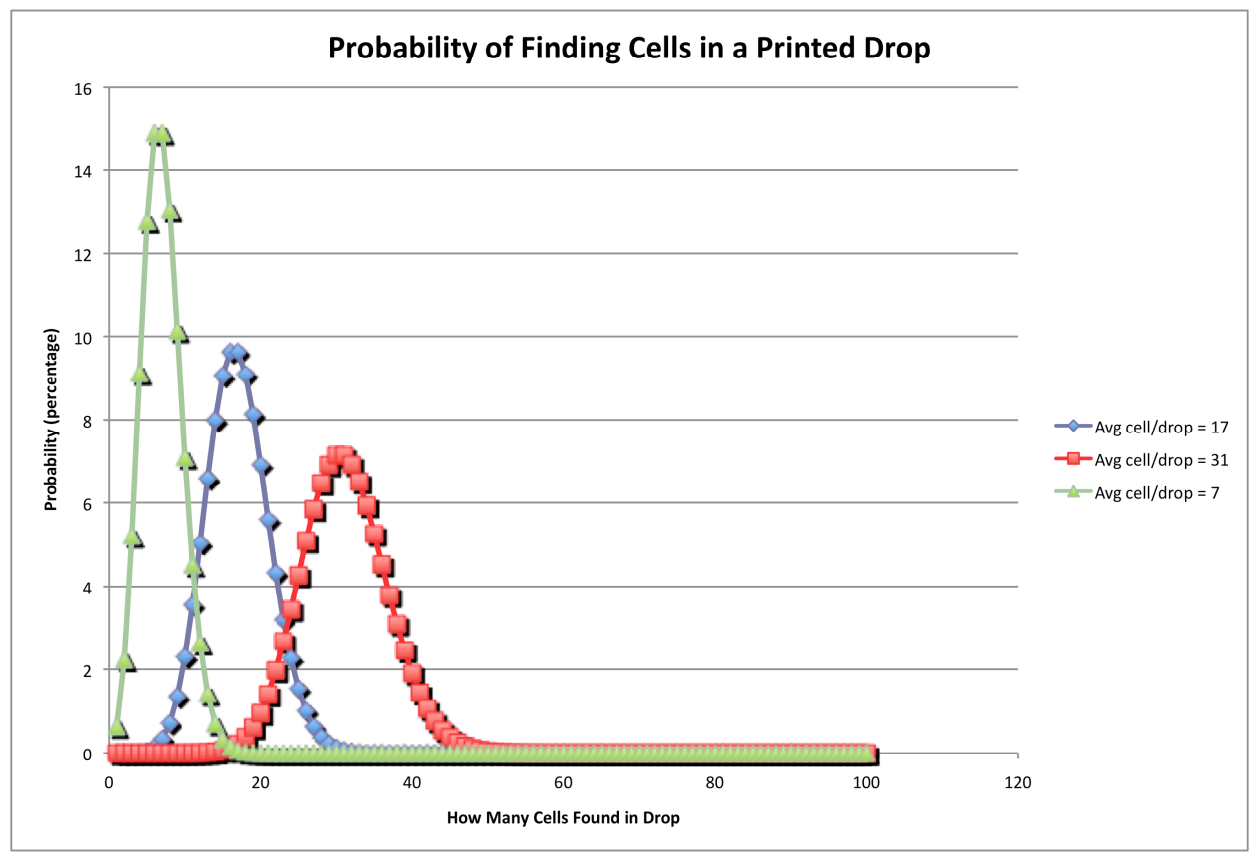

Figure 4.3 Poisson distributions of various cell per drop averages

To put this distribution into perspective, two theoretical distributions are also considered. If the droplet is assumed to be a perfect sphere, the actual droplet would have a diameter of about $0.821 \mathrm{~mm}$, or $0.032 \mathrm{in}$. Assuming the inkjet valve is a perfect cylinder, that the cylinder contains the full volume of one drop, and that the cylinder has 
an inner diameter of 0.03 in., this theoretical valve would have a length of about 0.636 $\mathrm{mm}$. Keeping the same length but increasing the inner diameter to $0.04 \mathrm{in}$, this would theoretically increase the droplet volume to about $0.516 \mu \mathrm{L}$. Using the first relationship defined above and using this larger droplet volume with the same cell concentration, this larger droplet would theoretically contain about 31 cells on average. While the probability of finding only one cell per droplet decreases to about 1.07E-10 percent, the larger diameter would have an even better chance of dispensing multiple cells per drop, as shown by the red curve in Figure 4.3. Now, if the valve diameter were decreased to 0.02 in, the droplet volume could drop to about $.129 \mu \mathrm{L}$, resulting in 7 cells per drop on average. This lower average shifts the Poisson distribution to the left, as shown by the green curve in Figure 4.3. As a result, the probability of finding just one cell per droplet increases to about 0.63 percent, but the overall probability of finding more than one cell per droplet decreases.

As shown by the above examples, a larger diameter valve may actually improve the performance of a cell-depositing system. The accuracy of the fluid deposit may not be as precise, but to improve the likelihood for cell proliferation. However, if the system were also to be used for fabricating a scaffold, precision would be desired. In this case, a smaller diameter would be preferred. In such a situation, where both functions are desired, at least two different-sized nozzles could be used, in which a larger nozzle would be used for cells, and the smaller nozzle would be used for scaffolding material. 


\section{$\underline{5.0}$ DEVELOPING THE CELLULAR INKJET SYSTEM}

The goal for this research project was to determine whether a commercially available, solenoid-based inkjet system could be used as a viable cellular deposition system. Initially, the inkjet system was intended to become the foundation for a custom 3D rapid prototyping system, similar in concept to the 3DP system developed at MIT. One long-term goal for this project would be to add the ability to print scaffolds. If cell viability can be confirmed, then it should also be possible to further develop this system into a fully functional scaffold rapid prototyping device with the capability for simultaneous seeding of cells.

\subsection{Materials and Hardware}

A few considerations with the materials and hardware needed to be taken into account when the system was designed. First, the materials and hardware used in this project needed to be biologically inert. Furthermore, because biohazardous compounds would be used, the hardware and materials needed to be sterilizable, as well as easily accessible and operable by an operator wearing protective gear. Lastly, the hardware components needed to be readily available and relatively affordable; the target cost range of parts for this system was below $\$ 5000$.

\subsubsection{Hardware}

A Marsh Unicorn inkjet printer (VideoJet Technologies, Wood Dale, Illinois) was used for its several inkjet heads. These inkjet heads were originally linked with a manifold to a single input source. However, once this manifold was removed, these 
seven inkjet heads could be filled with separate fluids, which potentially allowed the system to serve multiple functions. For example, one inkjet head could have contained a binder solution needed to cross-link the substrate bed; a different head could have also deposited cells into strategic locations onto the recently formed solid layer, maximizing potential for tissue growth. With seven total inkjet valves available, the system could have fabricated complex constructs. With respect to tissue engineering concerns, the inkjets used in this printer should have been harmless to cells. These inkjet heads, INKX0503450A (The Lee Co., Westbrook, Connecticut), were neither thermal nor piezoelectric, but were instead solenoid valves. These valves provided response times as fast as $0.25 \mathrm{~ms}$ and low power consumption, which lead to low operating temperatures under normal loading conditions.

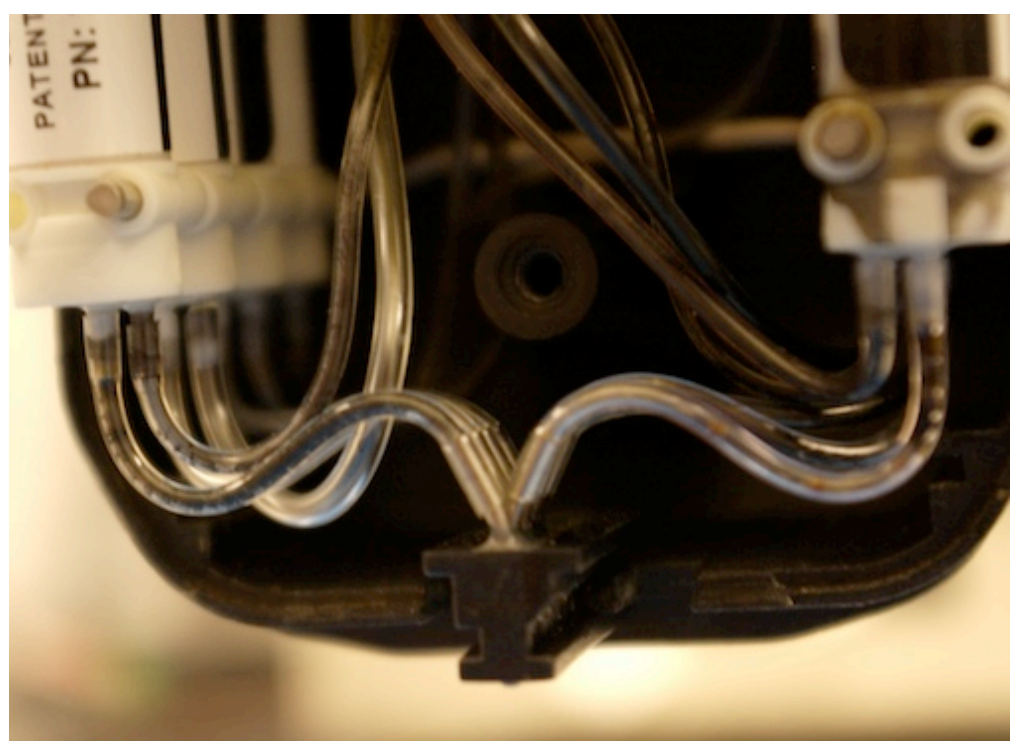

Figure 5.1 Inside the printer, showing the nozzle array and print heads 
Unlike thermal inkjets, which heated the fluid to eject it, the Lee valves required fluid to be already pressurized in order to flow once the valve opened. To pressurize the fluid in this system, pressurized gas was fed into the fluid reservoir. This gas was not used to aerosolize the fluid, as in a continuous inkjet system. Instead, the gas simply provided a pressure gradient to generate flow throughout the inkjet head. The very first iteration of the system utilized an AC-powered compressor to provide compressed air. This setup allowed for a somewhat mobile system. As long as an AC source was available, the system was usable. However, very early in the testing, the compressor seized. At this point, other options for pressurizing the system were considered. While another compressor could have provided an easily transportable source of pressurized gas, the cost of replacing the equipment would have been quite expensive. An appropriate compressor would have had to output sterile air, since the gas was originally intended to contact the fluid. This requirement would have required the use of an oil-free compressor, which were quite expensive. Furthermore, using another compressor would have again presented the risk of mechanical breakdown.

Because of the potential issues with using compressors, the decision was made to switch to compressed gas canisters. Compared to most compressors, compressed gas cylinders were not as portable. Furthermore, because the gases were compressed to a high pressure, great care needed to be taken when handling cylinders. However, gas cylinders offered the highest reliability, since no mechanical parts were needed (apart from a regulator). The reduced portability was also a non-issue, since this system was not going to travel outside a clean environment. Furthermore, because there was no mechanics involved, the gas supply possibly contained less aerosolized oil than gas from 
a compressor. The cost of a cylinder, depending on the gas used, was usually more affordable when compared to a compressor. For example, at AirGas West, a local gas supplier, $100 \mathrm{cu}-\mathrm{ft}$ of compressed air costed $\$ 5.35$. Assuming an airtight seal, this cylinder could have potentially lasted for months.

Initial testing of the gas-cylinder-powered setup utilized compressed $\mathrm{CO}_{2}$ to pressurize the system. While this worked fine to dispense Milli-Q water to ensure basic functionality, $\mathrm{CO}_{2}$ would have been an improper gas to use if cells were going to be used. $\mathrm{CO}_{2}$ could have made the media more acidic, killing the cells; furthermore, this gas could have reduced the percentage of oxygen available to the cells. Therefore, compressed air (AirGas West, San Luis Obispo, California) was substituted for the $\mathrm{CO}_{2}$ tank. According to official drawings from The Lee Co., the solenoid valves had a maximum operating pressure of $10 \mathrm{psi}$. The compressed air cylinder was pressurized to around 20,000 psi. Therefore, a regulator was added to reduce the output pressure to $10 \mathrm{psi}$.

In the modified design, the system allowed the compressed air to directly contact the loaded fluid. While this reduced mechanical complications that could occur with moving parts, another problem associated with this fix needed to be resolved. If the gas supply were contaminated, the cells would become at risk for contamination. To address this concern, PharmAssure vent filters (Pall Medical, East Hills, New York) were added in between the gas supply and fluid reservoir. This filter was chosen for a couple of reasons. First, the filter's inlet and outlet connectors utlized luer-lock connectors. This connector allowed for easy assembly when working in the sterile hood. The more important reason for using this filter was its $0.2-\mu \mathrm{m}$ hydrophobic membrane, which was commonly used in pharmaceutical companies for filtration purposes. 


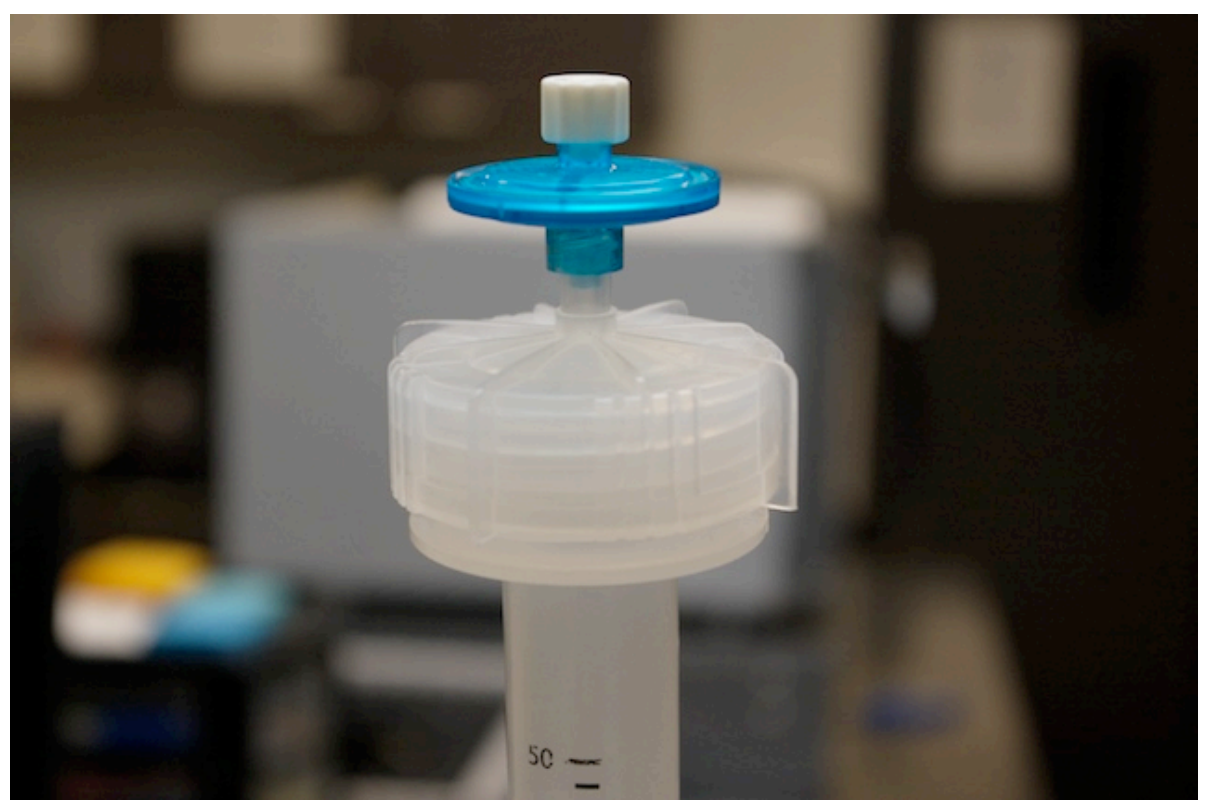

Figure 5.2 A sample vent filter is attached to top of syringe screwcap

It is worth noting that, while a $0.2-\mu \mathrm{m}$ pore size was treated as an industry standard, the FDA did not formally designate a standard pore size for filters. Rather, the administration defined a challenge using the organism Brevundimonas (Pseudomonas) diminuta. To qualify as a sterilizing filter, the filter had to retain at least 107 organisms per $\mathrm{cm}^{2}$ of filter area [60]. Therefore, by using $0.2-\mu \mathrm{m}$ filters, which passed the challenge, most microorganisms that might be present in the gas supply would have been prevented from contaminating the cells.

Additional hardware was required to be able to control the custom hardware via a computer. To provide a modular and scalable hardware environment, equipment from National Instruments was chosen. A NI PXI-7334 motion controller (National Instruments, Austin, Texas) in a 6-slot PXI chassis (National Instruments), connected to a computer via a PXI-to-PCI card (National Instruments), provided the computer to hardware interface. The I/O ports of the motion controller output a 5V TTL signal. 
Initially, a simple 5VDC relay was used to switch open the valves. The TTL signal from the motion controller was used as the relay's switching signal, while a DC Regulated Power Supply (Extech Instruments, Waltham, Massachusetts) provided 12VDC of power output for the solenoid valve. This setup, however, proved to be dangerous to the valves. While no apparent damage was seen, the external body of the valve became very hot. Upon consulting with a Lee Co engineer, it was determined that the valve was being overdriven.

Therefore, to trigger the valve but not risk damaging the hardware, an IECX0501350AA spike-and-hold circuit (The Lee Co) replaced the relay circuit. Like the relay, this pre-built circuit provided the solenoid valve with a $12 \mathrm{VDC}$ pulse to open the valve, but then kept the valve open using a lower hold voltage so as to not overdrive it. Upon substitution with the spike-and-hold circuit, a difference in operating temperature was immediately noticed; the exterior wall of the valve was no longer burning to the touch. To quantify the operating temperature, a thermocouple, attached to a multimeter, contacted the exterior wall of the valve and temperatures were recorded every minute as the valve repeatedly dispensed with a $32 \mathrm{~ms}$ pulse train. With this circuit, external body temperatures did not exceed beyond $23^{\circ} \mathrm{C}$, even with repeated, long periods of holding the circuit open. While this temperature was too cold for ideal cell living conditions, it was not too hot to denature proteins. 


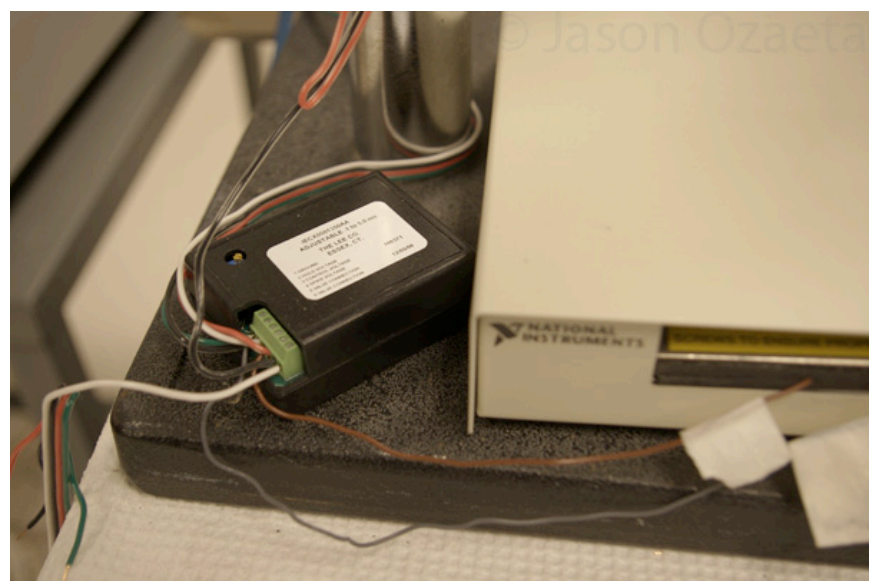

Figure 5.3 Spike and hold circuit with power and inkjet wires connected

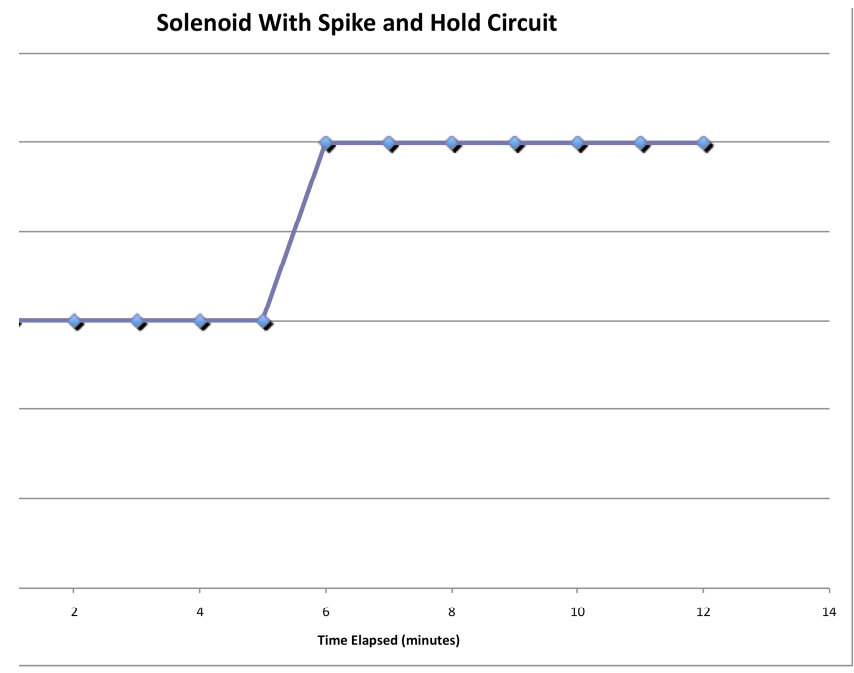

Figure 5.4 Chart plotting detected solenoid temperatures during repetitive dispensing

Building upon the original goal of developing a rapid prototyping system with the inkjet, some motion hardware was modified to be used with National Instruments equipment. Two stepper motors, Zeta 57-51 (Compumotor, Rohnert Park, California), and beds provided a two-dimensional platform. In order to control this $2 \mathrm{D}$ bed, the motors were wired to a MID-7602 stepper power drive (National Instruments) to provide power to the motors. The purpose of this hardware was to allow for automated, positioned fluid deposition. The $2 \mathrm{D}$ bed would have provided $\mathrm{XY}$ positioning for 
fabrication of the current layer. A third motor would have provided Z-axis motion to raise or lower the build platform. While the $2 \mathrm{D}$ bed was wired for use with the motion controller and was already functional, the cell viability tests did not utilize any motion to minimize potential sources for contamination. Future projects, however, could utilize the hardware to experiment with cell patterning.

Based off the expenses for this project, the cell depositor was relatively cheap compared to a commercial rapid prototyping system. The suggested retail price for the least expensive ZCorp 3D Printer was about $\$ 19,000$. In contrast, most of the components used in this project could have been obtained for under $\$ 10,000$ total (see Appendix G). With institutional discounts, however, the cost to purchase the majority of the hardware was reduced to the $\$ 6000$ range. The most expensive components, by far, were from National Instruments. However, this sub- $\$ 6000$ cost even included the cost of the stepper power drive, which was not used. Although the inkjet valves were provided at no cost, the hardware expense calculation included the cost of seven valves and spikeand-hold circuits.

\subsubsection{Materials}

Nalgene 180 PVC tubing (Thermo Fischer Scientific, Rochester, New York), which resisted many chemicals and was biocompatible, was chosen to link the compressed air supply to the syringe inlet. This tubing was also used to create a luer-lock interface at the outlet of the syringe. To make everything easy to assemble, as well as allow for use of the sterilizing filters, luer-lock adapters (Value Plastics Inc., Fort Collins, Colorado) were fitted onto the tubing ends. A $50 \mathrm{~mL}$ polypropylene screw-cap reservoir 
(AutoMate Scientific, Berkeley, California) served as the inkjet fluid reservoir. Because the reservoir and its assembly parts also came in contact with cells, they needed to be autoclavable in order to be safely placed in the laminar flow hood. The rest of the tubing, while also autoclavable, did not need to be autoclaved, as it would have been exposed to the environment after assembly and was sterilized in some fashion. For example, the tubing between the gas supply and reservoir had a vent filter at the reservoir end to sterilize the air that contacts the cells.

On the other end, the tubing that went from the reservoir to the inkjet inlet was sterilized using a 2.5\% diluted glutaraldehyde solution (Sigma-Aldrich, St. Louis, Missouri) prior to use. Glutaraldehyde was chosen for a couple of reasons. First, it was

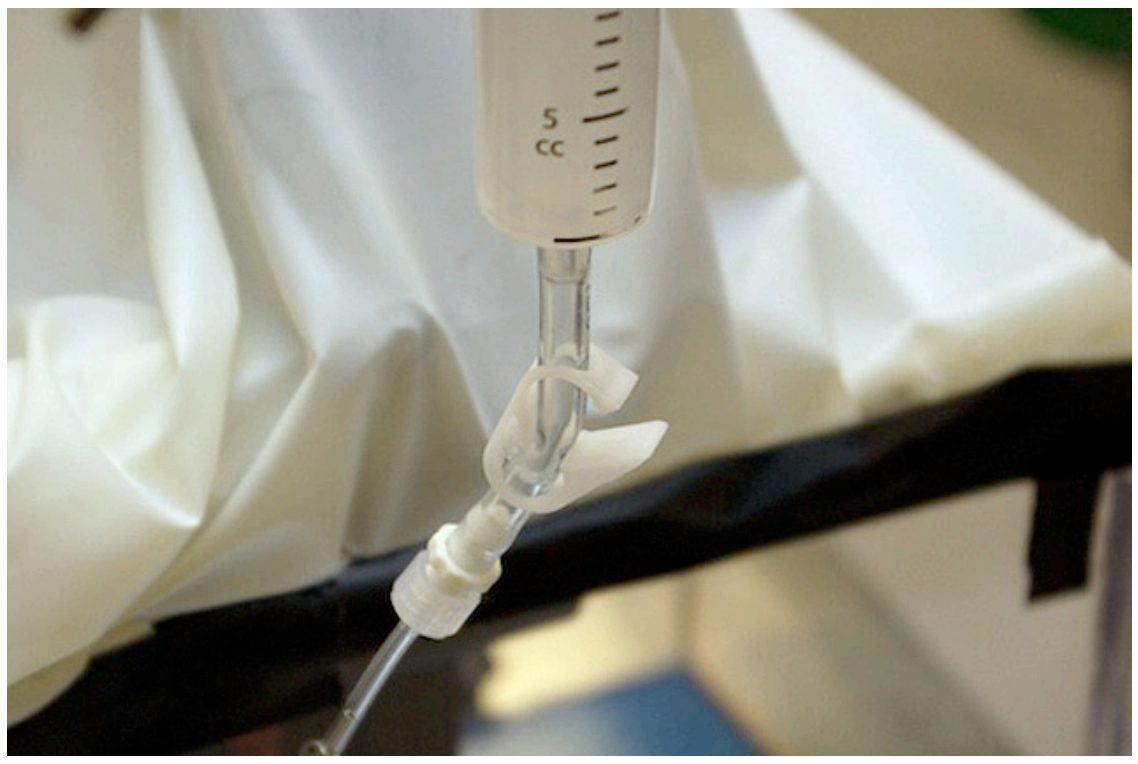

Figure 5.5 Nalgene tubing with pinch clamp and luer-locks on syringe tip

readily available in the lab where the inkjet system resided. Second, glutaraldehyde was non-corrosive to a variety of materials, including rubber and plastics used in this project. On the other hand, glutaraldehyde presented some minor health risks to humans. Short- 
term exposure to this chemical was shown to cause some respiratory and skin irritation; long-term exposure, however, could have lead to skin sensitization or asthma [58]. Furthermore, glutaraldehyde was also toxic to water organisms. Therefore, this chemical needed to be handled in the laminar flow hood with protective gear to minimize any exposure and had to be carefully disposed of to not harm the environment.

A simple cabinet was built to minimize exposure of the inkjet head to the environment. The design was comprised of a five-sided enclosure with a stretchable material covering the last side. The inkjet head was integrated with the stretchable material. This design characteristic would allow the cabinet to move while keeping the inkjet head in a stationary position above the cabinet's floor. With this style, the cabinet would have to be mounted atop a 2D stage to allow computer-controlled positioning to take place. 0.220 -inch-thick acrylic was used to construct the five walls. Plexiglas, an inert material, would allow for easy viewing as the system is in operation. Furthermore, it is much more robust than glass. However, this material could graze with prolonged exposure to solvents. Since alcohol would be used in the protocol to wipe down the cabinet, future revisions should use glass or a solvent-resistant plastic. For the stretchable cover, latex sheets (Small Parts Inc, Miramar, Florida) were used. This material was chosen for its low cost. However, like acrylic, it is sensitive to solvents like alcohol. Buna-N, also known as nitrile, would be a more appropriate material, as it is solvent resistant. An attempt was made to use this material, but the chosen sheet was too thick to be elastic. 


\subsubsection{Software}

From the project's conception, LabView (National Instruments) was chosen as the software development platform for the system. The integration between NI's hardware and LabView, as well as the user-friendly graphical programming interface, made LabView an easy choice. In order to control the digital I/O of the motion controller (as well as the 2D bed), the NI-Motion library was installed with LabView.

A simple virtual instrument (VI), called Cleaning.vi, was created to control sterilization of the internal inkjet components that cannot be autoclaved. The VI was designed to run over a ten-hour duration, in which glutaraldehyde was slowly dispensed through the printer. Every 30 seconds, a quick $15 \mathrm{~ms}$ voltage spike caused the solenoid to dispense a drop of glutaraldehyde. In addition, every five minutes, ten $15 \mathrm{~ms}$ pulses, which were intended to help dislodge any dead cells or organisms, took place. This pattern of increasing volume continued over the course of a half-hour; every ten minutes, $5010 \mathrm{~ms}$ pulses took place, and every 20 minutes, $10015 \mathrm{~ms}$ spikes took place.

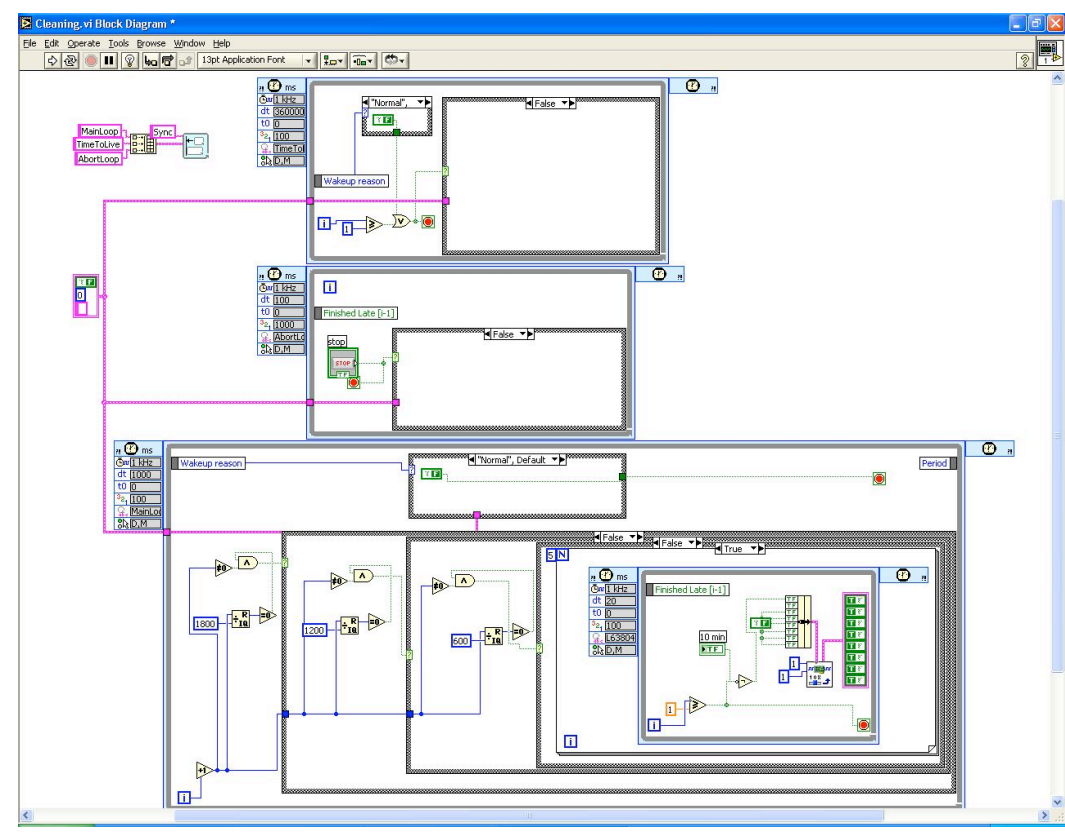

Figure 5.6 Cleaning.vi with 10-minute case shown at bottom 
Finally, after every half-hour, a full, one-second spike replaced the contact area with fresh glutaraldehyde. After ten hours, the VI automatically paused its execution. Following the sterilization, it was necessary to purge the system of any remaining glutaraldehyde, as it harmed any cells it came in contact with. Therefore, the operator had to manually activate a glutaraldehyde purge function of the VI, which repeatedly dispensed the remaining fluid until stopped by the operator. After the glutaraldehyde purge, an optional media purge was available. This function was added to ensure that no glutaraldehyde remained in the system. If activated, this function flushed the system with media that was loaded by the user following the glutaraldehyde purge.

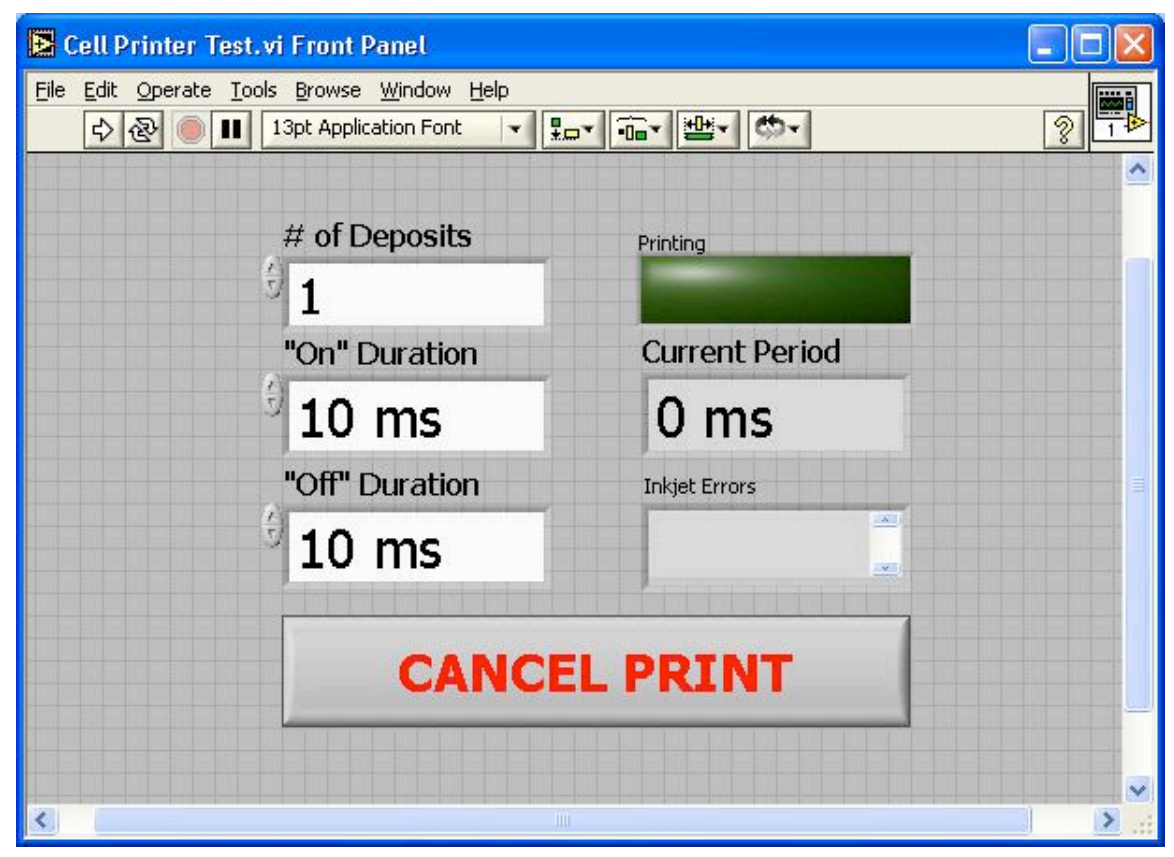

Figure 5.7 Cell printer test VI with default values set 


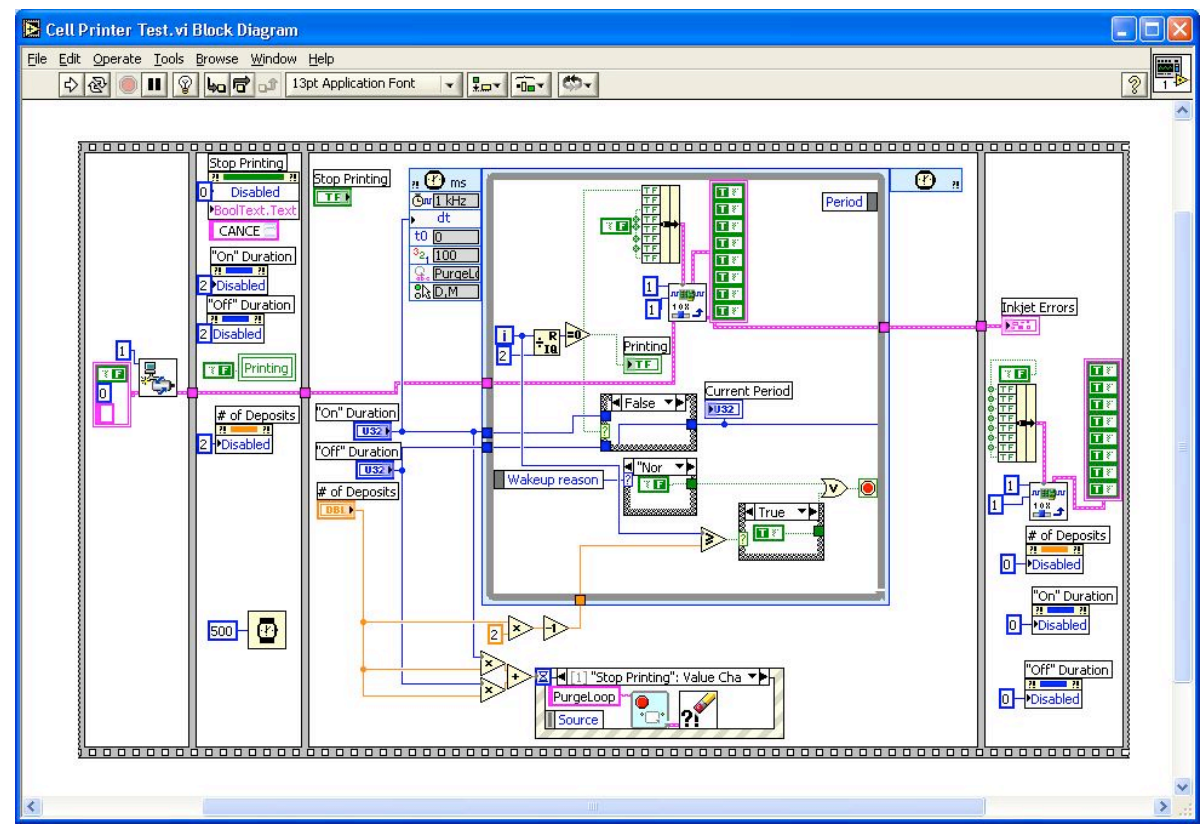

Figure 5.8 Block diagram of the cell printer test VI

A separate VI was created for running cell viability tests. While relatively simple, this VI provided some control over the depositing process. A control was added to change the open-valve duration. Furthermore, an additional control was added to specify the duration of the closed-valve state. By default, the open and closed states had the same $10 \mathrm{~ms}$ duration. The ability to specify how many times to dispense fluid was also included; by default, the VI only dispensed fluid once. If this value was greater than '1', then the VI waited to dispense the next drop using the closed-valve duration.

\subsection{Testing for Viability}

Before any future work can be carried on with the system's development, the system needed to be shown to safely print cells. As a result, cell viability needed to be assessed in this project. While not intended to provide a thorough test of the system, this initial viability test had to demonstrate that at least one living cell could be safely 
dispensed by the system with the designed protocols. If successful, this test would have provided proof-of-concept evidence in support of the solenoid-based inkjets.

\subsubsection{Cell-specific Resources and Caveats}

For this specific viability test, NIH 3T3-L1 mouse fibroblasts were used in the system. This cell type was fairly robust and reached confluence in a short amount of time. Additionally, the materials needed to sustain the cell type were relatively common. For example, a complete medium needed for this cell type could have consisted, at a minimum, of 10\% fetal bovine serum (Sigma-Aldrich) in Dubeco's Modified Eagles Medium. To minimize the risk of contamination in the medium, $1 \%$ of penicillin/streptomycin and Fungizone was added to the medium. While the quick growth rate of this cell type was advantageous, confluence needed to be carefully monitored. If the cells were to reach complete confluence, they would have begun to differentiate into adipocytes. Therefore, the cells were usually passaged at a rate of 1:10 to increase the time to reach confluence.

\subsubsection{Maximizing Sterility}

Although this system was far from usable, sterility was an issue that needed to be addressed. The ultimate goal for this system was to create a fully-seeded scaffold. If this system was ever to be used to actually create implantable tissues, then it had to meet FDA requirements for sterility. These requirements were put in place to maximize patient safety when receiving implants. Therefore, an attempt was made to build sterility into the system. 
A number of researchers used various techniques to clean their inkjet systems. In a study by Pardo et al., inkjet cartridges were thoroughly rinsed in deionized water up to 100 times, then alternatively rinsed in ethanol and water [44] before being loaded with the "ink." With this technique, the group was able to successfully print self-assembling monolayers onto gold substrates. This technique was also adopted by Roth et al. to print smooth muscle cells onto a coated, glass coverslip [47]. Boland et al. used a similar technique with the inkjet cartridges they used, except they only rinsed the cartridge several times [7]. However, in addition to rinsing the cartridge, the group placed their entire printer assembly and cartridge in a laminar flow hood and UV irradiated overnight. With this technique, Boland et al. were able to successfully print a scaffold and simultaneously dispense cells onto the scaffold.

A number of steps needed to be taken to ensure the system would be as sterile as possible. First, any components outside the inkjet enclosure that came in direct contact with the cells without passing through a filter needed to be fully sterilized. Therefore, the syringe reservoir, adapters, and tubing linking the reservoir to the inkjet inlet were autoclaved; these parts remained sealed in its sterile pouch until the cells were ready to be loaded. Once the cells were ready, the reservoir was assembled inside the laminar flow hood, following aseptic procedure. The reservoir remained in the laminar flow hood until the bottom port was pinched shut, the solution loaded, and the reservoir capped and topped with the vent filter. By following this procedure, contamination to the internal portion of the reservoir was kept to a minimum as the fully assembled reservoir was removed from the laminar flow hood. 


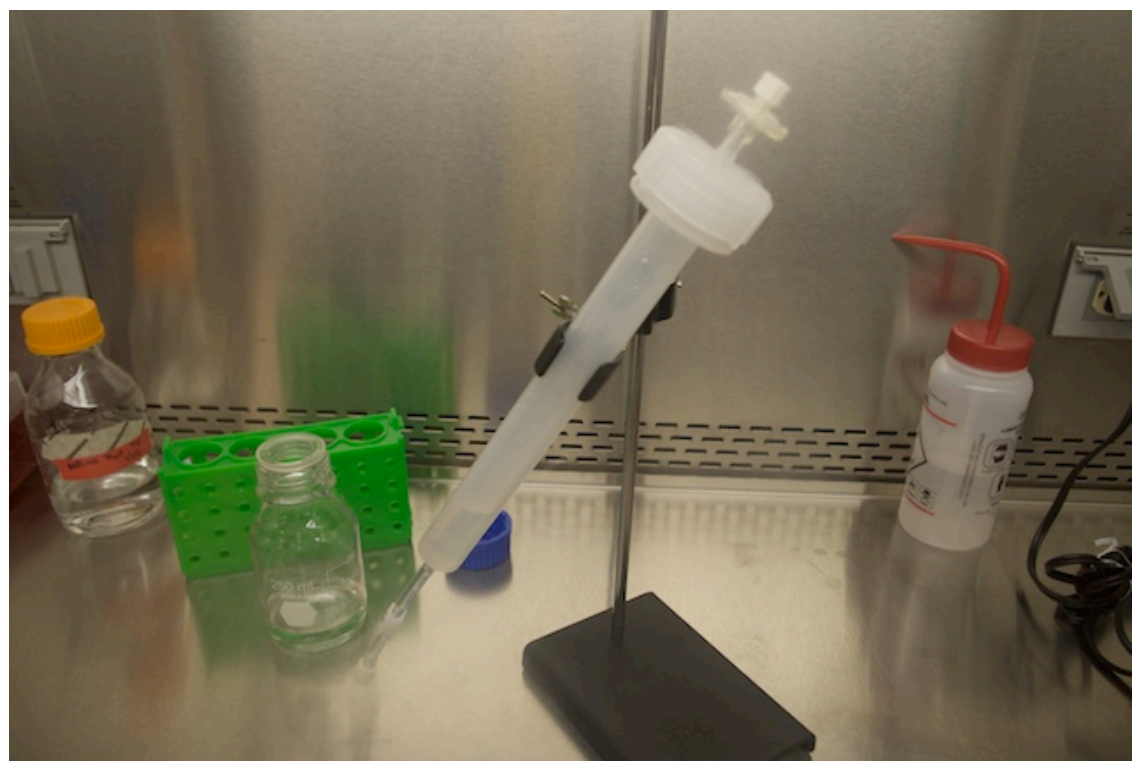

Figure 5.9 An assembled reservoir in laminar flow hood, filled with 2.5\% glutaraldehyde

A protocol, sufficient enough to maximize sterility for this half of the system, was more challenging to create. The main problem was with the printer heads. These valves could not be simply autoclaved, as it had electronic components and other wetted materials that were not suitable in high temperatures. Placing the entire system in a flow hood was considered; its sheer size, however, made this an unlikely option. Furthermore, should the $2 \mathrm{D}$ stage be integrated with the system, concerns with contaminants from the stages' lubrication made the entire system unfeasible for the shared hood. Therefore, the issue of maximizing sterility with the inkjet system was tackled by separating the environment from the internal system.

The strategy to maximize sterility of the internal system involved purging the fluid path with a fluid. In this strategy, any components after the reservoir that came in contact with the cell solution was cleaned using a known sterilant. For this experiment, a diluted glutaraldehyde solution was the sterilant of choice. As mentioned earlier, the 
cleaning VI was programmed to dispense this sterilant over the course of ten hours. This duration was chosen because it was the average contact time for similar glutaraldehyde solutions cleared for use as sterilants by the FDA [59]. Ideally, this solution would suffice if the internal components remained completely isolated. However, the system could become at risk upon changing of the fluid reservoirs, as the internal tubing would become exposed upon disengagement of the luer locks. An additional filter was considered but not used because the opening of the filter would have also been exposed upon disengagement. Therefore, to minimize this risk, any reservoir-swapping procedure in the protocols was quickly performed to limit the time the tubing was exposed. An alternate solution could have been to connect the tubing in the laminar flow hood, though this method would have required extra precautions to ensure the tubing was sterile. Furthermore, since the connecting components had to be external to the flow hood, the risk of contamination at the connection point still remained. As a result, this alternative was not implemented.

\subsubsection{Testing Methodology}

The goal for this thesis was to develop an inkjet system that can successfully dispense living cells onto a substrate. While other commercial inkjet technologies and systems have been successfully used in previous research projects, the inkjet system utilized in this project was untested for use in tissue engineering applications. Therefore, the inkjet heads and protocols developed for this custom system needed to be tested to evaluate its potential. The highest priority for any cell-capable printing system was to 
demonstrate cell viability during and immediately after printing [40]. Therefore, before any work can continue to further develop this system, cell viability had to be ascertained.

In order to obtain cells for testing, a trial run with cells was performed with the inkjet system. A day before the trial, three disassembled reservoirs were autoclaved according to protocol (see Appendix B). One reservoir was filled and loaded with 2.5\% glutaraldehyde (see Appendices B \& C) while the printing chamber was cleaned, then the cleaning VI was allowed to run overnight (see Appendix F). After purging the remaining glutaraldehyde, the second reservoir was filled with sterile media, loaded into, and purged through the system to ensure all traces of glutaraldehyde were removed. Finally, the third reservoir was prepared for use. At this time, the cells were removed from the incubator and re-suspended with fresh media in the cell laminar flow hood. The cells were then moved to the shared hood and transferred into the reservoir and control container, explained below. This reservoir was then carefully loaded into the system and printed into a sterile culture plate for assessment.

A simple control was also created to compare the inkjet results with. Before the reservoir was loaded with fluid, the fresh cell suspension was divided into two even batches. These batches were randomly assigned to one of two groups. One group was loaded into the reservoir and printed. The batch assigned to the other group remained in the laminar flow hood and was not printed. Theoretically, the only difference between both groups should have been that one group underwent the inkjet process. In reality, the printed cells also were briefly exposed to a non-aseptic environment; however, because only the immediate cell viability was being evaluated, this factor was considered negligible. 


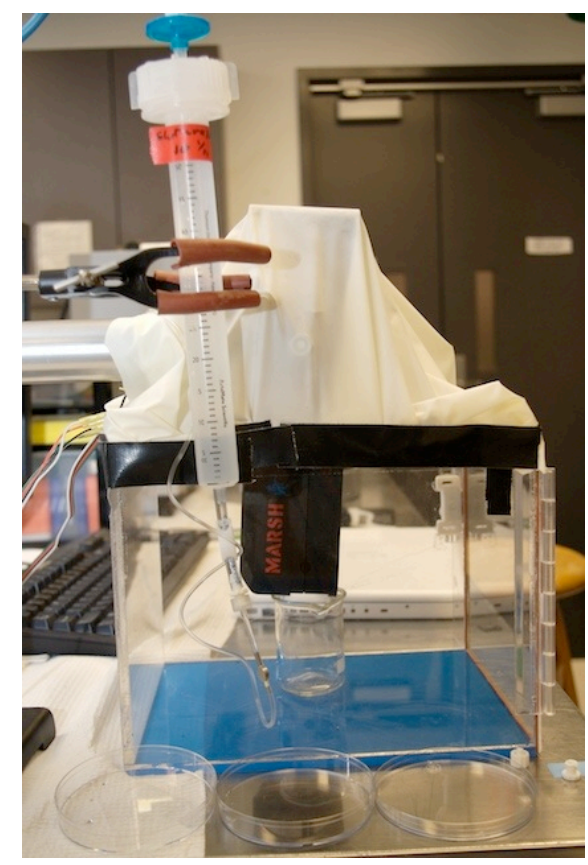

Figure 5.10 Inkjet system during purging with 2.5\% glutaraldehyde

To evaluate cell viability, a trypan blue exclusion assay was performed on the cells (see Appendix E). To perform this assay, a cell suspension was created by first trypsinizing then centrifuging cells into a pellet, then re-suspending in phosphate buffer solution (Sigma-Aldrich). This suspension was then mixed with $0.4 \%$ trypan blue (Sigma-Aldrich), and about $10 \mu \mathrm{L}$ of the mixture was placed into a hemocytometer (INCYTO, South Korea). Normally, cells are colorless in appearance. Trypan blue, which is a staining dye, cannot penetrate the outer membrane of cells; because of this fact, viable cells will continue to appear colorless when exposed to trypan blue. Nonviable cells, however, will stain blue, as the dye is able to penetrate the membrane and stain the cytoplasm. Under the hemocytometer, both viable and non-viable cells can then be counted to determine the percent viability. 
The trypan blue exclusion assay was performed twice to evaluate the effect of the printing process on the two blocks. First, immediately after assigning the two batches to their group, a 50- $\mu \mathrm{L}$ sample of cell solution from each batch was taken. The sample from each batch went through the trypan blue assay to obtain a cell viability count, which served as a baseline measurement. Another assay was performed on both groups immediately after the print group underwent the printing process.

\subsection{Issues Encountered}

Initial test-runs of the system revealed a number of technical issues, which was expected from an untested design. The first issues encountered were related to the cleaning process. In the first trial of the cleaning process, the glutaraldehyde was loaded properly into the system and set to dispense overnight using the cleaning VI; after the 10hour process completed, however, it was observed that only 5-7 $\mathrm{mL}$ of the $50 \mathrm{~mL}$ actually dispensed. Inspection of the system revealed that at some point during the process, all available air pressure was lost. The cause for the pressure loss was believed to be a minimally opened gas cylinder that was supplying gas too slowly. Despite this irregularity, the internals of the inkjet system did still receive the 10-hour contact time. This issue was resolved by simply opening the valve more to provide enough airflow to counter any leaks. Once pressure was restored to the system, the glutaraldehyde was purged, and media was flushed through the system following the protocol.

Ironically, once the low dispensing problem was resolved, a subsequent test of the cleaning VI with a full $50 \mathrm{~mL}$ of glutaraldehyde then resulted in a completely empty reservoir after the ten-hour runtime. Evaluation of the code revealed that the one-second 
drop intervals alone resulted in $150 \mathrm{~mL}$ of fluid being dispensed, based on a measured flow rate of $.290 \mu \mathrm{L} / \mathrm{ms}$ from the nozzle. Therefore, in order to have a surplus of glutaraldehyde remaining to ensure a complete ten-hour contact-time, the cleaning VI was modified, removing the one-second interval, which left the 30 -second interval as the shortest interval. This revised cleaning algorithm should have resulted in a fluid surplus between $20-30 \mathrm{~mL}$ if the syringe was filled to $50 \mathrm{~mL}$. A subsequent run after making the change resulted in a $25 \mathrm{~mL}$ surplus, which suggested the algorithm's performance was now correct.

An issue with the trypan blue test required changes to the protocol. A cell suspension, this time known to be near confluent, was printed through the system. The original recipe for the trypan blue exclusion test called for $1 \mathrm{~mL}$ of PBS to re-suspend a centrifuged cell pellet from $1 \mathrm{~mL}$ of suspension, and $10 \mu \mathrm{L}$ of trypan blue. An alternative recipe, which consisted of $200 \mu \mathrm{L}$ of cell suspension, $300 \mu \mathrm{L}$ of PBS, and $500 \mu \mathrm{L}$ of trypan blue, was also tested. However, upon examining the samples from either recipe in a hemocytometer, a "grainy" pattern was observed. Rather than seeing cells either transparent or filled with blue, the entire hemocytometer showed what seemed to be grains of trypan blue. It was not clear which cells were viable and non-viable. Reexamining all the supplies used, the root cause of the problem was found to be the media used. The DMEM used in the trial already contained FBS. Research about trypan blue indicated that the staining molecule attaches to serum proteins. Therefore, instead of entering non-viable cells, the trypan blue was instead binding with proteins in the FBS/DMEM culture medium, resulting in the grainy blue slide. It was also believed that the PBS used was of a 10X concentration, which could have caused osmotic lysis. To 
resolve this issue, a simpler trypan blue recipe was used, which consisted of $50 \mu \mathrm{L}$ of resuspended cells and $50 \mu \mathrm{L}$ of trypan blue. To re-suspend the centrifuged cells this time, serum-free DMEM-F12 media was used. These changes resulted in usable hemocytometer slides.

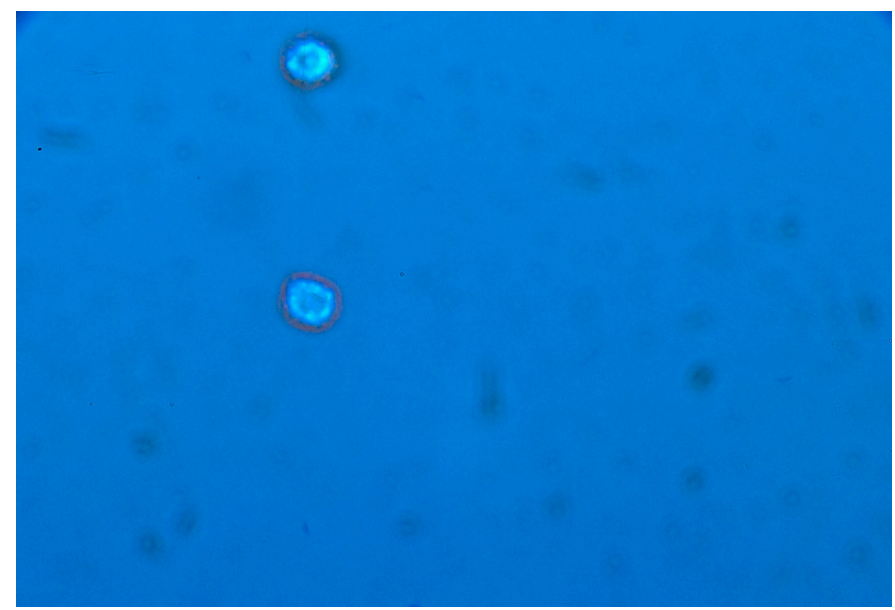

Figure 5.11 Light microscope showing viable cells in a printed solution

A problem that involved some of the luer-lock surfaced repeatedly during the printing process. Following any printing or purging, the connection between the syringe and inlet tubing of the inkjet head often became stuck. Efforts to loosen the luer-locks by hand often failed, sometimes requiring pliers to apply extra torque. It was first believed that the glutaraldehyde was possibly bonding the two luer-locks together. Glutaraldehyde was known to be non-corrosive to metals, rubbers, and plastics, but was also known to leave behind a sticky residue. To test this sticky hypothesis, a tightened luer lock was submerged in $2.5 \%$ glutaraldehyde overnight. The following morning, attempts to loosen the lock by hand failed. To work around this issue, the luer-locks were no longer secured tightly; instead, the locks were screwed until they barely formed a seal. Although this 
workaround may have temporarily worked, this issue might also have shared similar causes with the final issue, described below.

The most limiting issue experienced thus far was the printer nozzle becoming clogged. After a number of prints with the system, the nozzle became clogged. The source of the clog was located at the exit nozzle of the printer assembly. An attempt to unclog the nozzle by increasing air pressure failed after the syringe outlet tubing burst free from the syringe. This result raised the issue of tubing security, especially since electronic components were being used around the system. To continue operation of the system, a temporary workaround, which consisted of rerouting the solenoid outlet tubing to an unused, unclogged nozzle, was enacted. While this temporarily resolved the issue, the cause was not known at the time of occurrence. It was later realized that the media purge process was most likely the reason for the clog. The culture media contained nutrients important in cell reproduction. Part of this milieu consisted of amino acids, which were vital for protein synthesis. Since glutaraldehyde is a fixative, any leftover sterilant would have polymerized these amino acids upon contact, which would have formed into a gelatinous solid. As subsequent sterilizations occurred, more of the solid probably formed and aggregated until the printer nozzle eventually clogged. Therefore, in order to resolve this issue, the protocol would have to be modified to utilize an inert fluid, like saline, rather than culture media. Furthermore, this saline flush should be performed over a long time period, as glutaraldehyde was known to persist through flushes longer than originally expected. 


\subsection{Results}

The initial test with cells only tested for signs of cell viability. The printing procedure was performed as outlined in section 5.2.3. For each block, a single sample of cell solution was taken. As shown in Figure 5.12, a 96.8\% cell viability was observed from the single sample taken after printing.

\begin{tabular}{l} 
Specify values in this section!!!!!!!! \\
\hline \\
\hline
\end{tabular}

\begin{tabular}{l|r|r|r|r|}
\multicolumn{2}{c|}{ Automatically tabulated data! Do not edit below this line! } \\
\hline \hline & Test Group - Before & Test Group - After & Control - Before & Control - After \\
\hline Cells Alive & 30 & 54 & 42 \\
Cells Dead & 2 & 1 & 1 & 0 \\
Total Cells & 68 & 31 & 55 & 42 \\
\% Viability & $97.1 \%$ & $96.8 \%$ & $98.2 \%$ & $100 \%$ \\
Average Cells/square & 13.6 & 6.2 & 11 & 8.4 \\
Cell Density (cells/mL) & $1.36 \mathrm{E}+05$ & $6.20 \mathrm{E}+04$ & $1.10 \mathrm{E}+05$ & $8.40 \mathrm{E}+04$ \\
\% Reduction in Density & $\mathrm{n} / \mathrm{a}$ & $54.4 \%$ & $\mathrm{n} / \mathrm{a}$ & $23.6 \%$ \\
\hline
\end{tabular}

Figure 5.12 Calculated data from print vs. control group

\subsection{Discussion of Results}

The print results gave somewhat promising data. This data showed that some printed cells could survive the printing process. Due to the low sample size and single tests performed on each block, however, not much inference can be made between the blocks or other research. However, since the purpose of this project was just to provide a proof-of-concept for a possible cell printer design, detailed experimental data was not important. It is possible, however, that subsequent studies, if conducted, could provide this statistical comparison with the other cell printing research already published. With the promising result shown above, performing this subsequent work on the system to determine its true potential would definitely be justified. 


\subsection{FUTURE WORK AND CONSIDERATIONS}

This project aimed to introduce a system capable of rapid prototyping a scaffold, as well as simultaneously seeding cells. In order to make this task possible, a commercial inkjet system was gutted, integrated with LabView hardware, and modified to allow multiple materials to be used. In addition, the framework for 2D motion with stages was laid out. Once functional in LabView, the system was further modified to facilitate for the safe integration of cells.

While the limits of the system are currently being determined in a separate project, initial tests using the system do show potential for the system. The initial results support a need for further study to determine the full potential of the system in its current version. The numerous problems experienced along the way, however, also demonstrate that more work is needed to optimize the system.

\subsection{What Needs to Be Done}

Although it has been demonstrated that cells can survive the printing process through the developed system, more work needs to be performed to improve the system. For example, while immediate survival of cells has been demonstrated, a limit needs to be determined for the cells during the printing process. The RP process can be a slow and tedious process, often taking hours to complete a model. In its current state, the cell printer is unable to support living cells for more than 20 minutes. Therefore, the system needs to be modified to provide "life support" while the cells wait both in the system and on the printed substrate. This life support system would most likely require a humid, temperature-controlled and print environment. Furthermore, a way to maintain a $5 \% \mathrm{CO}_{2}$ 
atmosphere within this environment might be necessary to fully simulate incubator conditions.

Continuing on the topic of limits, the operating limits of the system also need to be determined. While some limits, such as maximum operating pressure, are already known, the clogged valve experienced during testing demonstrated that the system does have a limited capacity for cell population. A maximum density needs to be determined to ensure that the system will not become clogged again. Protocol changes may also need to be implemented. For example, another purge cycle follow cell printing should be considered to ensure that any remaining cells get removed.

Second, the resolution of the system needs to be drastically improved. Currently, the system is only capable of printing dots in the millimeter range. Articles discussed in this paper mention resolutions in the micron scale. In order to have any relevance in cell depositing, this system needs a significant increase in resolution. Because the inkjet valves used in this project were taken from a system intended to print large text on boxes, it is possible that the hardware is not capable of reaching a minute resolution. Therefore, hardware changes might be necessary to improve the resolution. While smaller volume solenoid valves are available from The Lee Co., using piezoelectric inkjet heads is not of the question.

Third, for the system to have any relevance in creating 3D models, two things need to be accomplished. First, some existing hardware would need to be replaced in the system. For example, the motion controllers used in this project are only capable of 2D movement. Therefore, if a third stepper stage were to be added for Z-axis motion, the motion controller would need to be replaced. Position sensing would be another ideal 
addition into the system. There is currently no real feedback system to determine where the stage is in its vector space. The system does have home sensors and forward/reverse sensors to know when it reaches the home position and maximum travel allowable. The system "guesses" its position by how many steps the motors have turned. While this method would be adequate for generic inkjet applications, a more accurate positioning system would be required if the system will be used to dispense cells on the micron scale. One method to gain accurate positioning could be to add encoders to the stage setup. Encoders have a sensor that read a calibrated scale, and convert that reading into a position. By adding three encoders to each stage and providing the feedback via the stepper motor drivers into the VIs, accurate position would be possible if paired with a smaller-diameter nozzle. It should be worth noting that once these hardware changes take place, the LabView VIs already created would have to be modified to handle the extra dimension and positional feedback.

In addition to adding better position detection, the overall design needs to be modified to allow movement of the inkjet head rather than the build platform. The need for this design change becomes apparent if the system were to be modeled after a 3D bioplotter. The liquid bed would easily become unstable if it were mounted to a $2 \mathrm{D}$ stage. Therefore, in order for the system to successfully transform into a 3D rapid prototyping system, an overhead 2D-motion stage that can accommodate the inkjet head needs to be built. The Z-axis movement, however, can still raise or lower the build platform. Because of these changes, the chamber design will also need to be modified in order to enclose the overhead stage. 
Finally, although other inkjet systems have dispensed scaffolding material, this system has not been tested with such materials. The solenoid valves could theoretically be adapted for either a 3D Printing or 3D plotting setup. Lam et al. have already shown that a 3DP-based system could fabricate biocompatible scaffolds. Furthermore, Pfister et al. have demonstrated that 3D plotters can also be used to fabricate biocompatible scaffolds. To fully utilize its potential, the system's compatibility with scaffolding materials needs to be established. If the system can dispense scaffolding material, such as PCL, then it should be possible to create a fully bioactive scaffold from scratch.

\subsection{Conclusion}

With demand for organs outpacing the available supply, tissue engineering has attempted to ease this deficit. The limitations of traditional tissue engineering, however, have pushed researchers to investigate other methods of tissue fabrication. This research project has focused on one such tangent of tissue engineering research: tissue rapid prototyping. Various RP technologies investigated by previous studies indicate that most of these technologies could be used in some form of TE research.

This research project aimed to establish the foundation for a tissue rapid prototyping system based on a relatively unused subset of inkjet technology. The findings from this demonstrate that printed cells can survive through the designed cellprinter system. Although the long-term survival rates have yet to be determined with this setup, the initial positive results indicate that further research with the system should take place. With multiple inkjet heads available and flexibility in the software and hardware environment, it should be possible to refine the system into a tool that can fabricate pre- 
seeded tissue engineering constructs, which should be better able to develop into tissues when compared to tissues created using traditional methods. 


\subsection{REFERENCES}

1. Alberts, Bruce, Alexander Johnson, Julian Lewis, Martin Raff, Keith Roberts, and Peter Walter. Molecular Biology of the Cell. $4^{\text {th }}$ Edition. New York: Garland Science, 2002.

2. Alvarez-Barreto, Jose F. and Vassilios I. Sikavitsas. "Tissue Engineering Bioreactors." Tissue Engineering. John P. Fisher, Antonios G. Mikos, and Joseph D. Bronzino, eds. New York: CRC Press, 2007.

3. Atala, Anthony, Stuart B. Bauer, Shay Soker, James J. Yoo, and Alan B. Retik. "Tissue-Engineered Autologous Bladders for Patients Needing Cystoplasty." Lancet 367 (2006): 1241-1246.

4. Bafan, Marco Mehran M. "Evaluation and Analysis of Tissue Engineering Principles in the Design and Fabrication of Scaffolds." MS thesis. California Polytechnic State University, San Luis Obispo, 2004.

5. Beeson, Robert and Robert D. Rung. "Thermal Inkjet Technology - Review and Outlook." White paper. Corvallis, Oregon: Hewlett-Packard Company.

$<$ http://www.hp.com/oeminkjet/reports/techpress_3.pdf $>$

6. Boland, Thomas, Vladimir Mironov, Anna Gutowska, Elisabeth. A. Roth, and Roger R. Markwald. "Cell and Organ Printing 2: Fusion of Cell Aggregates in Three-Dimensional Gels." The Anatomical Record Part A: Discoveries in Molecular, Cellular, and Evolutionary Biology 272A.2 (2003): 497-502.

7. Boland, Thomas, Xu Tao, Brook J. Damon, Brian Manley, Priya Kesari, Sahil Jalota, and Sarit Bhaduri. "Drop-on-Demand Printing of Cells and Materials for Designer Tissue Constructs." Materials Science and Engineering C.27 (2007): 372-376.

8. Burg, K. J. L., W. D. Holder, Jr., C. R. Culberson, R. J. Beiler, K. G. Greene, A. B. Loebsack, W. D. Roland, P. Eiselt, D. J. Mooney, C. R. Halberstadt. "Comparative Study of Seeding Methods for Three-Dimensional Polymeric Scaffolds." Journal of Biomedical Materials Research 51.4 (2000): 642-649. Figure reprinted with permission of John Wiley \& Sons, Inc.

9. Chu, T. M. G., J. W. Halloran, S. J. Hollister, and S. E. Feinberg. "Hydroxyapatite Implants With Controlled Architectures." Journal of Materials Science: Materials in Medicine 12 (2001): 471-478.

10. Chu, T. M. Gabriel, David G. Orton, Scott J. Hollister, Stephen E. Feinberg, and John W. Halloran. "Mechanical and In Vivo Performance of Hydroxyapatite Implants With Controlled Architectures.” Biomaterials 23 (2002): 1283-1293. Figure reprinted with permission from Elsevier. 
11. Coleman, Rhima M., Natasha D. Case, Robert E. Guldberg. "Hydrogel Effects on Bone Marrow Stromal Cell Response to Chondrogenic Growth Factors." Biomaterials 28 (2007): 2077-2086.

12. Cooper, James A., Janmeet S. Sahota, W. Jay Gorum II, Janell Carter, Stephen B. Doty, and Cato T. Laurencin. "Biomimetic Tissue-engineered Anterior Cruciate Ligament Replacement." Papers of the National Academy of Sciences 104.9 (2007): 3049-3054.

13. Culvier, Damien, Olivier Rossier, Patricia Bassereau, and Pierre Nassoy. "Micropatterned 'Adherent /Repellent' Glass Surfaces for Studying the Spreading Kinetics of Individual Red Blood Cells Onto Protein-Decorated Substrates." European Biophysiology Journal 32 (2003): 342-354.

14. Dooling, Dave. "Bioreactor Expands Health Research." Fact sheet. 8 Sep 1998. National Aeronautics and Space Administration. Accessed 27 Mar 2008. $<$ http://science.msfc.nasa.gov/newhome/br/bioreactor.htm $>$

15. Farach-Carson, Mary C., Roger C. Wagner, and Kristi L. Kiick. "Extracellular Matrix: Structure, Function, and Applications to Tissue Engineering." Tissue Engineering. John P. Fisher, Antonios G. Mikos, and Joseph D. Bronzino, eds. New York: CRC Press, 2007.

16. Fuchs, Julie R., Boris A. Nasseri, and Joseph P. Vacanti. "Tissue Engineering: A 21st Century Solution to Surgical Reconstruction." The Annals of Thoracic Surgery 72.2 (2001): 577-591.

17. Giordano, Russell A., Benjamin M. Wu, Scott W. Borland, Linda C. Cima, Emanuel M. Sachs, and Michael J. Cima. "Mechanical Properties of Dense Polylactic Acid Structures Fabricated by Three Dimensional Printing." Journal of Biomaterials Science: Polymer Edition 8.1 (1996): 63-75.

18. Glicklis, Rachel, Lilia Shapiro, Riad Agbaria, Jose C. Merchuk, and Smadar Cohen. "Hepatocyte Behavior Within Three-Dimensional Porous Alginate Scaffolds." Biotechnology and Bioengineering 67.3 (2000): 344-353.

19. Gustavsson, Per, Fredrik Johansson, Martin Kanje, Lars Wallman, and Cecilia Eriksson Linsmeier. "Neurite Guidance on Protein Micropatterns Generated by a Piezoelectric Microdispenser.” Biomaterials 28 (2007): 1141-1151.

20. Halbleib, M. T. Shurk, C. de Luca, D. von Heimburg, and H. Hauner. "Tissue Engineering of White Adipose Tissue Using Hyaluronic Acid-based Scaffolds: invitro Differentiation of Human Adipocye Precursor Cells on Scaffolds". Biomaterials 21.24 (2000): 2589-2598.

21. Heath, Carole A. "Cells for Tissue Engineering." Trends in Biotechnology 18.1 (2000): 17-19. 
22. Hersel, U., C. Dahmen, and H. Kessler. "RGD Modified Polymers: Biomaterials for Stimulated Cell Adhesion and Beyond." Biomaterials 24 (2003): 4385-4415.

23. Hulmes, D.J. "Building Collagen Molecules, Fibrils, and Suprafibrillar Structures." Journal of Structural Biology 137 (2002): 2-10.

24. Kaczynski, Julie Baars. "What is the 3DP Process?" Three Dimensional Printing. 28 June 2000. Massachusetts Institute of Technology. Accessed 29 November 2007. <http://www.mit.edu/ tdp/whatis3dp.html>

25. Kim, Stephen S., Hirofumi Utsunomiya, John A. Koski, Benjamin M. Wu, Michael J. Cima, Jane Sohn, Kanae Mukai, Linda G. Griffith, and Joseph P. Vacanti. "Survival and Function of Hepatocytes on a Novel Three-Dimensional Synthetic Biodegradable Polymer Scaffold With an Intrinsic Network of Channels." Annals of Surgery 228.1 (1998): 8-13. Figures pending reprint permission from Lippincott Williams \& Wilkins.

26. King, Michael W. "Extracellular Matrix." The Medical Biochemistry Page. 22 Mar 2006. Indiana University School of Medicine. 16 Oct 2007. $<$ http://web.indstate.edu/thcme/mwking/extracellularmatrix.html $>$

27. Klebe, Robert J., Charles A. Thomas, George M. Grant, Anne Grant, and Paramita Gosh. "Cytoscription: Computer Controlled Micropositioning of Cell Adhesion Proteins and Cells." Journal of Tissue Culture Methods 16 (1994): 189192.

28. Krampera, Mauro, Giovanni Pizzolo, Giuseppe Aprili, and Massimo Franchini. "Mesenchymal Stem Cells for Bone, Cartilage, Tendon and Skeletal Muscle Repair.” Bone 39 (2006): 678-683.

29. Lam, C. X. F., X.M. Mo, S.H. Teoh, and D.W. Hutmacher. "Scaffold Development Using 3D Printing With a Starch-Based Polymer." Materials Science and Engineering C.20 (2002): 49-56.

30. Landers, R., A. Pfister, U. Hübner, H. John, R. Schmelzeisen, and R. Mülhaupt. "Fabrication of Soft Tissue Engineering Scaffolds By Means of Rapid Prototyping Techniques." Journal of Materials Science 37 (2002): 3107-3116.

31. Landers, Rüdiger, Ute Hübner, Rainer Schmelzeisen and Rolf Mülhaupt. "Rapid Prototyping of Scaffolds Derived From Thermoreversible Hydrogels and Tailored for Applications in Tissue Engineering." Biomaterials 23 (2002): 4437-4447. Figure reprinted with permission from Elsevier.

32. Le, Hue P. "Progress and Trends in Ink-Jet Printing Technology." Journal of Imaging Science and Technology 42.1 (1998): 49-62. Figures reprinted with permission of IS\&T: The Society for Imaging Science and Technology. 
33. Lee, G. and J. W. Barlow. "Selective Laser Sintering of Bioceramic Materials For Implants." Proceedings of Solid Freeform Fabrication Symposium. Austin, TX: August 9-11, 1993: 376-380.

34. Lewis, Jennifer A. "Direct Ink Writing of Three-Dimensional Ceramic Structures." Journal of the American Ceramic Society 89.12 (2006): 3599-3609.

35. Martin, R., David Burr, and Neil Sharkey. Skeletal Tissue Mechanics. New York: Springer Science+Business Media, 2004.

36. Meinel, Lorenz, Vassilis Karageorgiou, Robert Fajardo, Brian Snyder, Vivek Shinde-Patel, Ludwig Zichner, David Kaplan, Robert Langer, and Gordana Vunjak-Novakovic. "Bone Tissue Engineering Using Human Mesenchymal Stem Cells: Effects of Scaffold Material and Medium Flow." Annals of Biomedical Engineering 32.1 (2004): 112-122.

37. Merrin, Jack, Stanislas Leiber, and John S. Chuang. "Printing Multistrain Bacterial Patterns with a Piezoelectric Inkjet Printer.” PLoS ONE 2.7 (2007): e663.

38. Mironov, Vladamir, Thomas Boland, Thomas Trusk, Gabor Forgacs and Roger D. Markwald. "Organ Printing: Computer-aided Jet-based 3D Tissue Engineering." TRENDS in Biotechnology 21.4 (2003): 157-160.

39. Mironov, Vladimir, Nuno Reis, Brian Derby. "Bioprinting: A Beginning." Tissue Engineering 12.4 (2006): 631-634.

40. Mooney, David, Linda Hansen, Joseph Vacanti, Robert Langer, Stephen Farmer, and Donald Ingber. "Switching From Differentiation To Growth In Hepatocytes: Control By Extracellular Matrix.” Journal of Cellular Physiology 151.3 (1992): 497-505.

41. Nakamura, Makoto, Akiko Kobayashi, Fumio Takagi, Akihiko Watanabe, and Yuko Hiruma. "Biocompatible Inkjet Printing Technique for Designed Seeding of Individual Living Cells." Tissue Engineering 11.11 (2005): 1658-1666.

42. Niklason, Laura E., William Abbott, Jinming Gao, Brian Klagges, Karen K. Hirschi, Kezban Ulubayram, Nancy Conroy, Rosemary Jones, Ami Vasanawala, Seema Sanzgiri, and Robert Langer. "Morphologic and Mechanical Characteristics of Engineered Bovine Arteries." Journal of Vascular Surgery 33.3 (2001): 628-638.

43. Osumi, M., N. Yamada and M. Toya. "Bacterial retention mechanisms of membrane filters." PDA Journal of Pharmaceutical Science and Technology 50 (1996): 30-34.

44. Pardo, Laura, W. Cris Wilson Jr., and Thomas Boland. "Characterization of Patterned Self-Assembled Monolayers and Protein Arrays Generated by the Ink-Jet Method." Langmuir 19(2003): 1462-1466. 
45. Pfister, Andreas, Rüdiger Landers, Andres Laib, Ute Hübner, Rainer Schmelzeisen, and Rolf Mülhaupt. "Biofunctional Rapid Prototyping for TissueEngineering Applications: 3D Bioplotting versus 3D Printing." Journal of Polymer Science: Part A: Polymer Chemistry 42 (2004): 624-638.

46. Rayleigh, Lord. "On the Instability of Jets." Proceedings of the London Mathmatical Society 10.4 (1878): 4-13.

47. Roth, E. A., T. Xu, M. Das, C. Gregory, J. J. Hickman, and T. Boland. "Inkjet Printing for High-Throughput Cell Patterning." Biomaterials 25 (2004): 37073715.

48. Rücker, Martin, Matthias W. Laschke, Dominik Junker, Carlos Carvalho, Alexander Schramm, Rolf Mülhaupt, Nils-Claudius Gellrich, and Michael D. Menger. "Angiogenic and Inflammatory Response to Biodegradable Scaffolds in Dorsal Skinfold Chambers of Mice.” Biomaterials 27 (2006): 5027-5038.

49. Sanjana, Neville E. and Sawyer B. Fuller. "A Fast Flexible Ink-Jet Printing Method for Patterning Dissociated Neurons in Culture." Journal of Neuroscience Methods 136 (2004): 151-163.

50. Sasaki, Takako, Reinhard Fässler, and Erhard Hohenester. "Laminin: The Crux of Basement Membrane Assembly." The Journal of Cell Biology 164.7 (2004): 959-963.

51. Saunders, Rachel E., Julie E. Gough, and Brian Derby. "Delivery of Human Fibroblast Cells by Piezoelectric Drop-on-Demand Inkjet Printing." Biomaterials 29 (2008): 193-203.

52. Smith, Cynthia M. “A Direct-Write Three-Dimensional Bioassembly Tool for Regenerative Medicine.” Phoenix: The University of Arizona, 2005.

53. Smith, Cynthia M., Joseph Christian, William Warren and Stuart Williams. "Characterizing Environmental Factors that Impact the Viability of TissueEngineered Constructs Fabricated by a Direct Write Bioassembly Tool." Tissue Engineering 13.2 (2007): 373-383.

54. Stokolsa, Shula and Mark H. Tuszynski. "Freeze-Dried Agarose Scaffolds with Uniaxial Channels Stimulate and Guide Linear Axonal Growth Following Spinal Cord Injury." Biomaterials 27 (2006): 443-451.

55. Tan, K.H., C. K. Chua, K. F. Leong, C.M. Cheah, P. Cheang, M. S. Abu Bakar, and S. W. Cha. "Scaffold Development Using Selective Laser Sintering of Polyetheretherketone-Hydroxyapatite Biocomposite Blends." Biomaterials 24 (2003): 3115-3123. Figure reprinted with permission from Elsevier. 
56. Tay, B. Y., S.X Zhang, M.H. Myint, F.L. Ng, M. Chandrasekaran, L. K. A. Tan. "Processing of Polycaprolactone Porous Structure for Scaffold Development." Journal of Materials Processing Technology 182 (2007): 117-121.

57. Turcu, Florin, Karla Tratsk-Nitz, Solon Thanos, Wolfgang Schuhmann, and Peter Heiduschka. "Ink-jet Printing For Micropattern Generation of Laminin For Neuronal Adhesion." Journal of Neuroscience Methods 131 (2003) 141-148.

58. United States. Centers for Disease Control and Prevention. "Glutaraldehyde." International Chemical Safety Card No. 0158. US National Version. Apr 2000. National Institute for Occupational Safety and Health. Accessed 13 Jan 2008. < http://www.cdc.gov/niosh/ipcsneng/neng0158.html>

59. United States. Food and Drug Administration. "FDA-Cleared Sterilants and High Level Disinfectants with General Claims for Processing Reusable Medical and Dental Devices." Device Evaluation Information. 28 Sep 2006. Department of Health and Human Services. Accessed 1 Jan 2008.

$<$ http://www.fda.gov/cdrh/ode/germlab.html $>$

60. United States. Food and Drug Administration. Guidance for Industry: Sterile Drug Products Produced by Aseptic Processing - Current Good Manufacturing Practice. Rockville: Department of Health and Human Services, 2004.

61. United States. Health Resources and Services Administration. Healthcare Systems Bureau. Division of Transplantation. 2006 Annual Report of the U.S. Organ Procurement and Transplantation Network and the Scientific Registry of Transplant Recipients: Transplant Data 1996-2005. Rockville: Department of Health \& Human Services, 2006.

62. United States. National Institute of Health. NIH Funding of Research Using Specified Existing Human Embryonic Stem Cells. Notice NOT-OD-01-058. $<$ http://grants.nih.gov/grants/guide/notice-files/NOT-OD-01-059.html >

63. United States. National Institute of Health. Stem Cells: Scientific Progress and Future Research Directions. 17 Jun 2001. Department of Health and Human Services. Accessed 22 Mar 2008. < http://stemcells.nih.gov/info/scireport/2001report>

64. Varki, Ajit, Richard Cummings, Jeffrey Esko, Hudson Freeze, Gerald Hart, and Jamey Marth, eds. Essentials of Glycobiology. New York: Cold Spring Harbor Laboratory Press, 1999.

65. Wagner, M., N. Kiapur, M. Wiedmann-Al-Ahmad, U. Hübner, A. Al-Ahmad, R. Schön, R. Schmelzeisen, R. Mülhaupt, and N. C. Gellrich. "Comparative In Vitro Study of the Cell Proliferation of Ovine and Human Osteoblast-Like Cells on Conventionally and Rapid Prototyping Produced Scaffolds Tailored for Application as Potential Bone Replacement Material." Journal of Biomedical Materials Research Part A 83.4 (2007): 1154-1164. 
66. Wang, Wei-Gou, Si-Quan Lou, Xiao-Dong Ju, Kun Xia, and Jia-Hui Xia. "In Vitro Chondrogenesis of Human Bone Marrow-Derived Mesenchymal Progenitor Cells in Monolayer Culture: Activation by Transfection with TGF-ß2." Tissue \& Cell 35 (2003): 69-77.

67. Xu, Tao, Cassie A. Gregory, Peter Molnar, Xiaofeng Cui, Sahil Jalota, Sarit B. Bhaduri, and Thomas Boland. "Viability and Electrophysiology of Neural Cell Structures Generated by the Inkjet Printing Method." Biomaterials 27 (2006): 3580-3588.

68. Xu, Tao, Joyce Jin, Cassie Gregory, James J. Hickman, and Thomas Boland. "Inkjet Printing of Viable Mammalian Cells." Biomaterials 26 (2005): 93-99.

69. Yeong, Wai-Yee, Chee-Kai Chua, Kah-Fai Leong and Margam Chandrasekar. "Rapid Prototyping in Tissue Engineering: Challenges and Potentials." TRENDS in Biotechnology 22.12 (2004): 643-652.

70. Yoon, Diana M. and John P. Fisher. "Polymeric Scaffolds for Tissue Engineering Applications." Tissue Engineering and Artificial Organs. Joseph D. Bronzino, ed. New York: CRC Press, 2006.

71. Yoshioka, Yuka, Ghassan Jabbour, and Paul Calvert. "Multilayer Inkjet Printing of Materials." Proceedings of SPIE 4809 (2002): 164-166.

72. Zein, Iwan, Dietmar W. Hutmacher, Kim Cheng Tan, and Swee Hin Teoh. "Fused Deposition Modeling of Novel Scaffold Architectures for Tissue Engineering Applications." Biomaterials 23 (2002): 1169-1185. Figure reprinted with permission from Elsevier. 


\section{APPENDIX A - GLUTARALDEHYDE PREPARATION PROTOCOL}

\section{A.1 Materials \& Equipment}

- $\quad 25 \%$ Glutaraldehyde (Sigma-Aldrich)

- Milli-Q water

- $250 \mathrm{~mL}$ media bottle

- Plunger syringe w/ luer-lock tip

- $\quad 0.2-\mu \mathrm{m}$ syringe filter

- Sterile serological pipettes

- Laminar flow hood

\section{A.2 Safety}

- Perform procedure in laminar flow hood.

- Do not ingest or allow glutaraldehyde to come in contact with skin!

- Discard used pipettes and pipette tips in biohazard bin or used pipette tip container.

- Wear eye protection gloves, closed-toe shoes and pants during entire procedure.

\section{A.3 Set-Up}

A.3.1 If media bottle is not sterile, autoclave media bottle and cap.

A.3.2 Spray down work surface of laminar flow hood with IPA or ethanol and wipe with Kimwipe.

A.3.3 Spray outer surfaces of all containers and packages, then place in laminar flow hood. 


\section{A.4 Procedure}

A.4.1 Use plastic plunger syringe to take up non-sterile Milli-Q water.

A.4.2 Attach syringe filter to syringe tip, and dispense Milli-Q water into sterile media bottle. Remove syringe tip.

A.4.3 Repeat steps A.4.1 and A.4.2 until $90 \mathrm{~mL}$ of sterile water is dispensed. Discard syringe and filter.

A.4.4 Using an unused $10 \mathrm{~mL}$ serological pipette, add $10 \mathrm{~mL}$ of $25 \%$ glutaraldehyde solution to media bottle. Discard pipette. 


\section{APPENDIX B - INKJET RESERVOIR ASSEMBLY PROTOCOL}

\section{B.1 Materials \& Equipment}

- Bottle or vessel containing printer fluid

- $\quad 0.2$ micron vent filter (Pall Medical)

- $\quad 50 c c$ syringe with cap (Automate Scientific)

- $\quad$ " length of 1/8" ID PVC tubing (Nalgene)

- $\quad$ Tubing pinch-clamp

- Female luer-lock to $1 / 8$ " tubing barb adapter

- Female-luer-lock cap

- $\quad$ Self-sealing sterilization pouches

- Sterile serological pipettes

- Autoclave

- Laminar flow hood

\section{B.2 Safety}

- Ensure all caps are tightly screwed to ensure no leakage from syringe.

- Wear eye protection gloves, closed-toe shoes and pants when using hazardous chemicals.

\section{B.3 Set-Up}

B.3.1 Ensure that all components of assembly are disassembled.

B.3.2 Place tubing, luer-lock components, and pinch clamp in small sterilizing pouch and seal. 
B.3.3 Place syringe and cap (unscrewed from syringe) in large sterilizing pouch and seal.

B.3.4 Place pouches into autoclave and use "pouch" setting if available, otherwise autoclave for 20 minutes.

B.3.5 Spray down vessel containing printer fluid and autoclaved pouches, and place in flow hood.

B.3.6 Wear nitrile gloves and spray down with IPA or ethanol.

\section{B.4 Procedure}

B.4.1 Open pouches, remove tubing and pinch-clamp, insert tubing through openings of pinch-clamp, and pinch tubing shut.

B.4.2 Remove female luer-lock barb adapter from small pouch and insert onto either end of tubing.

B.4.3 Remove one male-threaded luer-lock cap from small pouch and tighten onto luer-lock.

B.4.4 Remove syringe from large pouch, and insert other end of tubing onto bottom nozzle of syringe.

B.4.5 Using a sterile serological pipette, add printer fluid into syringe.

B.4.6 Remove cap from large pouch, and screw cap tightly on syringe.

B.4.7 Remove vent filter from packaging and screw tightly onto syringe cap.

B.4.8 Remove one male-threaded luer-lock cap from small pouch and screw onto other end of vent filter. 


\section{APPENDIX C - INKJET LOADING PROTOCOL}

\section{C.1 Materials \& Equipment}

- Completed syringe reservoir from Appendix B

- Compressed air cylinder (AirGas West)

- Regulator w/ 1/8" ID tubing barb adapter

- 8000-0020, 1/8” ID tubing (Nalgene)

- MTLL230-1, male luer-lock to 1/8" ID barb adapter (Value Plastics)

- P-850X, Male luer-lock to 1/16" ID barb adapter (Upchurch Scientific)

- CFT-01-10, 1/16” ID tubing (Small Parts Inc)

- STCR 16/18, syringe tubing reducer (Small Parts Inc)

- TGY-050-10, 0.050” ID tygon tubing (Small Parts Inc)

\section{C.2 Safety}

- Ensure all caps and adapters are tightly screwed to ensure no leakage occurs.

- Wear eye protection gloves, closed-toe shoes and pants when using hazardous chemicals.

- Ensure regulator and cylinder are shut off and tubing pinched shut when disconnecting any tubing.

- Place gas cylinder between yourself and regulator when opening gas supply.

- Do not use equipment if gas connections are leaking. 


\section{C.3 Set-Up}

C.3.1 Attach one end of tygon tubing to inlet port of inkjet valve, and attach smaller diameter nozzle of syringe reducer to other end of tubing.

C.3.2 Attach one end of 1/16" ID tubing to larger nozzle of syringe reducer.

C.3.3 Insert barb of P-850X adapter into other end of 1/16" ID tubing.

C.3.4 Tighten FTLLP-1 cap on P-850X adapter.

C.3.5 Attach regulator to cylinder valve, following manufacturer's instructions.

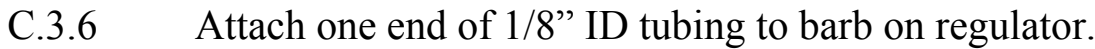

C.3.7 Attach barb of MTLL230-1 to other end of 1/8" ID tubing.

\section{C.4 Procedure}

C.4.1 Transfer completed reservoir assembly to ink-jet workbench and hold vertical using test tube clamp and stand.

C.4.2 QUICKLY remove luer-lock caps from both tubing-side of reservoir assembly and from P-850X adapter, then attach luer-locks. DO NOT OVERTIGHTEN LUER-LOCKS!

C.4.3 Remove luer-lock caps from both vent filter and from gas-supply tubing, then attach gas-supply tubing to vent filter.

C.4.4 Disengage pinch clamps on reservoir assembly tubing and gas-supply tubing.

C.4.5 Ensure regulator screw is loose by rotating screw counterclockwise.

C.4.6 Slowly turn cylinder screw counterclockwise to open cylinder valve, and allow regulator pressure to stabilize. Check for leaks.

C.4.7 Slowly turn regulator screw clockwise until low-pressure gauge reads 10 PSI.

C.4.8 Power on DC regulated power supply. 


\section{APPENDIX D - INKJET UNLOADING PROTOCOL}

\section{D.1 Materials \& Equipment}

- Loaded inkjet system from Appendix C

- Compressed air cylinder (AirGas West)

- Regulator w/ 1/8" ID tubing barb adapter

- 382213, Dual DC power supply (Extech)

- FTLLP-1, female luer-lock cap

\section{D.2 Safety}

- Ensure all caps are tightly screwed to ensure no leakage occurs.

- Wear eye protection gloves, closed-toe shoes and pants when using hazardous chemicals.

- Ensure regulator and cylinder are shut off and tubing pinched shut before disconnecting any tubing.

\section{D.3 Set-Up}

D.3.1 Use the purge feature in the current LabView VI to remove any remaining fluid stored in the reservoir.

D.3.2 Power down the dual power supply before disconnecting any tubing.

\section{D.4 Procedure}

D.4.1 Turn cylinder screw clockwise to shut off cylinder gas supply.

D.4.2 Turn regulator screw counterclockwise until diaphragm is disengaged. 
D.4.3 Shut off DC regulated power supply.

D.4.4 Loosen luer-lock between gas tubing and vent filter to bleed off excess air in low-pressure side of regulator.

D.4.5 Slowly turn regulator screw clockwise until air barely starts to flow through tubing. Vent remaining air until high-pressure gauge reads 0 PSI.

D.4.6 Use pinch-clamps to clamp gas tubing and syringe outlet tubing shut.

D.4.7 Tighten luer-lock cap onto gas tubing adapter.

D.4.8 QUICKLY disconnect ink-jet inlet tubing from reservoir outlet tubing and tighten luer-lock cover onto inkjet inlet tubing adapter. 


\section{APPENDIX E - TRYPAN BLUE ASSAY PROTOCOL}

\section{E.1 Materials \& Equipment}

- Cell solution

- $\quad 0.4 \%$ Trypan Blue solution (Sigma-Aldrich)

- Serum-free DMEM/Ham's F12 culture medium (Sigma-Aldrich)

- $50 \mathrm{~mL}$ centrifuge tube

- $1 \mathrm{~mL}$ centrifuge tube

- Sterile pipette tips

- $\quad 10-1000 \mu \mathrm{L}$ micropipettes

- Handheld tally counters

- DHC-N01, C-Chip disposable hemocytometer (INCYTO)

- Inverted microscope (Olympus)

\section{E.2 Safety and Notes}

- Perform procedure in laminar flow hood.

- Do not allow Trypan Blue or cell solution come in contact with skin.

- Wear eye protection gloves, closed-toe shoes and pants when using hazardous chemicals.

- Discard pipettes and pipette tips into biohazard bin or used pipette tip container.

- Count cells within 3-5 minutes of mixing suspension with trypan blue. Longer incubation periods will result in reduced viability counts. 


\section{E.3 Set-Up}

E.3.1 Spray down work surface of laminar flow hood with IPA or ethanol and wipe with Kimwipe.

E.3.2 Spray outer surfaces of all containers, then place in laminar flow hood.

\section{E.4 Procedure}

E.4.1 Using a sterile pipette tip, transfer $10 \mathrm{~mL}$ of cell suspension to centrifuge tube. Discard pipette tip.

E.4.2 Centrifuge suspension at $5 \mathrm{X}$ speed for 5 minutes. Discard supernatant.

E.4.3 Using a sterile pipette tip, transfer $50 \mu \mathrm{L}$ of serum-free culture medium to centrifuge tube and gently mix with pipette to resuspend pellet.

E.4.4 Using a sterile pipette tip, transfer cell suspension to small centrifuge tube.

E.4.5 When ready to count cells, use a sterile pipette tip and transfer $50 \mu \mathrm{L}$ of trypan blue to small centrifuge tube containing suspension. Pipette up and down gently to mix.

E.4.6 At both sides of hemocytometer inlets, use a $10 \mu \mathrm{L}$ pipette ot add trypan blue mixture until area with grid is fully exposed to mixture. DO NOT OVERFILL!

E.4.7 Place hemocytometer on stage of inverted microscope and adjust power to 100X magnification.

E.4.8 Use handheld counters to count blue cells while also counting non-blue cells. NOTE: Count cells that touch middle line of three-line border at top and left sides only; discard cells that touch middle line at bottom and right sides. 


\section{E.5 Calculations}

- $\quad$ cells $/ \mathrm{mL}=(\#$ cells counted $/ \#$ squares counted $) * 10^{4} *(1 / 5)$

- $\quad$ total cells $=$ cells $/ \mathrm{mL} * 0.2 \mathrm{~mL}$

- $\quad \%$ viability $=(\#$ non-blue cells $/$ total $\#$ of cells counted $) * 100$ 


\section{APPENDIX F - CELL PRINTER TEST PROTOCOL}

\section{F.1 Materials \& Equipment}

- Cell suspension

- $10 \mathrm{~mL}$ Dubeco's Modified Eagle's Medium

- $\quad 2.5 \%$ glutaraldehyde solution from Appendix A

- $\quad 3$ autoclaved, unassembled syringe assembly pouches

- Culture plate or petri dish

- Disposable $50 \mathrm{~mL}$ centrifuge tube

- PXI chassis (National Instruments)

- Dual DC-regulated power supply (Extech)

- Cell printer system

\section{F.2 Safety and Notes}

- Perform loading procedures in laminar flow hood.

- Do not allow Trypan Blue or cell solution come in contact with skin.

- Wear eye protection gloves, closed-toe shoes and pants when using hazardous chemicals.

- Discard pipettes and pipette tips into biohazard bin or used pipette tip container.

- Minimize how long cell suspension is away from incubator. 


\section{F.3 Set-Up}

F.3.1 Prepare 2.5\% solution of glutaraldehyde using Appendix A protocol.

F.3.2 Open cabinet door of cell printer and wipe down cabinet surface with ethanol or IPA.

F.3.3 Wipe down inkjet nozzles with IPA or ethanol. Close cabinet door.

F.3.4 Shut down computer.

F.3.5 Power on PXI chassis, ensuring only power light is on.

F.3.6 Power up computer. Load LabView 7.1.

\section{F.4 Procedure}

F.4.1 Open cabinet door, and place beaker beneath inkjet nozzles. Lower printer arm as much as possible to reduce splatter.

F.4.2 Assemble and fill one syringe reservoir with 2.5\% glutaraldehyde, following Appendix B protocol.

F.4.3 Assemble and fill one syringe reservoir with 5-10 mL of medium, following Appendix B protocol.

F.4.4 Load system with glutaraldehyde-filled reservoir, following Appendix C protocol.

F.4.5 Place disposable container beneath inkjet nozzles, and close cabinet door.

F.4.6 In LabView, open 'Cleaning.vi’

F.4.7 Click on Run button to begin cleaning process.

F.4.8 Once 10-hour cycle completes, click on Purge button to purge any remaining glutaraldehyde. IMPORTANT: Click on the Stop Purge button once inkjet dispenses only air at least 6 consecutive times.

F.4.9 Unload used reservoir from system, following Appendix D protocol.

F.4.10 Load system with medium-filled reservoir, following Appendix C protocol. 
F.4.11 In LabView, click on Start Media Purge button to flush system with medium. IMPORTANT: Click on the Stop Media Purge button once inkjet dispenses only air at least 6 consecutive times.

F.4.12 Unload used reservoir from system, following Appendix D protocol.

F.4.13 Remove disposable container from cabinet and discard.

F.4.14 Place culture plate/petri dish below inkjet nozzles. Lower inkjet head if necessary, and close cabinet door.

F.4.15 Assemble and fill one syringe reservoir with the cell suspension, following Appendix B protocol.

F.4.16 Load cell suspension reservoir into system, following Appendix C protocol.

F.4.17 In LabView, open 'Cell Printer Test.vi'

F.4.18 Configure number of deposits, "on" duration, and "off" duration to desired settings.

F.4.19 Click on the Run button to begin printing cells.

F.4.20 Once print is complete, cover culture plate/petri dish and remove from cabinet.

F.4.21 Place disposable container below inkjet nozzles and close cabinet.

F.4.22 In LabView, click on Purge button to purge any excess cell suspension from printer. IMPORTANT: Click on Stop Purge button once inkjet dispenses only air at least 6 consecutive times.

F.4.23 Seal, remove, and discard disposable container.

F.4.24 Perform Trypan Blue assay with suspension in culture plate/petri dish, following Appendix E protocol. 


\section{APPENDIX G - PARTS LIST}

\begin{tabular}{|c|c|c|c|c|}
\hline Manufacturer/Supplier & Part/Model \# & Description & Quantity / unit & Price / unit \\
\hline valueplastics.com & MTLL230-1 & 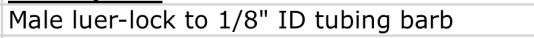 & 100 adapters & $\overline{\$ 14.00}$ \\
\hline valueplastics.com & FTLL230-1 & Female luer-lock to $1 / 8$ " ID tubing barb & 100 adapters & $\$ 12.00$ \\
\hline valueplastics.com & FTLLP-1 & Female luer-lock cap & 100 caps & $\$ 12.00$ \\
\hline valueplastics.com & MTLLP-1 & Male luer-lock cap & 100 caps & $\$ 7.00$ \\
\hline Pall Medical & HP2002 & $0.2 \mu \mathrm{m}, 25 \mathrm{~mm}$ vent filters & 50/box & \\
\hline Nalgene & $8000-0020$ & 180 PVC Tubing - FDA/USPVI - 1/8" ID & 50 feet & \\
\hline Small Parts Inc & TGY-050-10 & Tygon tubing, 0.050" ID & 10ft/unit & $\$ 6.20$ \\
\hline Small Parts Inc & CFT-01-10 & PVC tubing, $1 / 16 "$ ID & 10ft/unit & $\$ 1.25$ \\
\hline Small Parts Inc & STCR-16/18-01 & Syringe tubing reducer, $1 / 16 "$ to $0.050 "$ ID & 1 reducer & $\$ 16.85$ \\
\hline Upchurch Scientific & $P-850 X$ & Male luer-lock to $1 / 16^{\prime \prime}$ ID tubing barb & 10/pack & $\$ 6.65$ \\
\hline Automate Scientific & $06-50$ & $50 \mathrm{~mL}$ polypropylene screw cap reservoir & 1 syringe & $\$ 12.00$ \\
\hline INCYTO & DHC-N01 & C-Chip disposable hemocytometer & $50 /$ box & \\
\hline Sigma Aldrich & unknown & $25 \%$ glutaraldehyde & & \\
\hline Extech Instruments & 382213 & DC Regulated Power Supply & 1 unit & $\$ 199$ \\
\hline The Lee Co & IECX0501350AA & Spike \& Hold Circuit & 1 unit & $\$ 124.70$ \\
\hline AirGas West & & Compressed Air & $100 \mathrm{cu} \mathrm{ft}$. & $\$ 5.35$ \\
\hline Victor/Airgas & SR250C-590 & Single-stage Air Regulator & 1 unit & $\$ 180.12$ \\
\hline Compumotor (Parker) & Zeta 57-51 & Stepper Motor, size 23 frame & & \\
\hline The Lee Co & INKX0503450A & Inkjet valve & 1 unit & $\$ 111.33$ \\
\hline National Instruments & PXI-7334 & 4-axis motion controller & 1 unit & $\$ 1,169.10$ \\
\hline National Instruments & MID-7604 & Stepper Driver \& Power Unit & 1 unit & $\$ 2,249.10$ \\
\hline National Instruments & SCB-68 & Shielded 68-pin I/O Connector Block & 1 unit & $\$ 269.10$ \\
\hline
\end{tabular}

